\title{
Verteilungsmuster spätbronzezeitlicher Speichergruben in Mitteleuropa
}

\author{
Benedikt Biederer
}

\begin{abstract}
Zusammenfassung
Speichergruben waren in der Spätbronzezeit in ganz Mitteleuropa verbreitet und wurden, verglichen mit anderen Perioden, intensiv genutzt. Bei archäologischen Ausgrabungen zeigen sie sich in vielfältiger Verteilung sowohl im Vergleich mehrerer Fundplätze einer Region als auch im Vergleich ganzer Regionen. Innerhalb und außerhalb des eigentlichen Wohnbereiches lassen sich unstrukturierte oder strukturierte Verteilungsmuster, häufig auch kleinere oder größere Konzentrationen von Erdspeichern ausmachen. Ziel dieser Arbeit ist, diese Verteilungsmuster zu analysieren und dadurch unterschiedliche individuelle und kollektive Strategien in der Vorratshaltung von Lebensmitteln festzustellen. Es wird untersucht, in welchen Siedlungstypen und Regionen die jeweilige Speicherstrategie angewandt wurde und welche sozialen und ökonomischen Gründe dahinterstehen. Um die Quellenbasis zu vergrößern, werden historische Berichte in die Auswertung miteinbezogen.
\end{abstract}

\section{Schlüsselbegriffe}

Speichergruben, Getreide, Vorratshaltung, strukturierte Verteilung, Spätbronzezeit, Mitteleuropa.

\begin{abstract}
Distribution Patterns of Late Bronze Age Storage Pits in Central Europe

Storage pits were common throughout central Europe during the Late Bronze Age and were used extensively in comparison to other periods. The distribution of storage pits, as revealed by archaeological excavation, shows a considerable degree of diversity both between individual sites in the same region and between sites in different regions. Unstructured and structured distribution patterns involving larger and smaller numbers of pits can be defined and distinguished both inside and outside settlements. The work reported in this paper involves the analysis of these distribution patterns with the overall aim of identifying different individual and collective strategies for food storage. The paper investigates the strategies applied in different settlements and regions and proposes social and economic factors which may lie behind them. In order to enlarge the data base, historical reports have been included in the evaluation.
\end{abstract}

\section{Keywords}

Storage pits, grain, food storage, structured distribution, Late Bronze Age, central Europe.

\section{Einleitung}

In dieser Arbeit wird untersucht, wie Menschen in der späten Bronzezeit bis zum Übergang zur Eisenzeit ihre existenzielle Nahrungsvorratswirtschaft regelten und welche unterschiedlichen Strategien sie verfolgten. Am deutlichsten lässt sich dies anhand der Verteilung der Speichergruben in Siedlungen oder deren Aktivitätsbereichen nachvollziehen. Innerhalb von Mikroregionen wie auch im Vergleich größerer Gebiete zeichnet sich dabei eine große Diversität ab. An einigen Plätzen gruppieren sich die Speicher einzeln bei Häusern, während andernorts große Areale innerhalb oder außerhalb des eigentlichen Wohnareals angelegt wurden. Für die Untersuchung wurden geeignete Fallstudien aus Mitteleuropa herangezogen. Ausgewählt wurden Fundplätze, in denen Speicherstrategien klar fassbar sind und die möglichst großflächig untersucht und umfassend publiziert wurden. Sie werden in Abbildung 1 dargestellt.

Die Begriffe „Speichergrube“, „Vorratsgrube“ und „Erdspeicher“ werden in diesem Beitrag synonym genutzt. Die Identifizierung von Vorratsgruben erfolgt durch die Form der Befunde. Hierzu zählen grundsätzlich Gruben mit rundlichem Grundriss sowie nach oben konisch verjüngenden Wänden. Je nach Untergrund können die Wände flacher oder steiler ausgebildet sein, wobei eine möglichst kleine Öffnung angestrebt wurde, um sie wirkungsvoll abzudichten. $\mathrm{Zu}$ beachten ist, dass erosive Vorgänge wie Verstürze nachträglich zur Veränderung der Form geführt haben können. Speichergruben durch botanische Untersuchungen als solche nachzuweisen ist schwierig, da es sich beim Inhalt meist nicht mehr um das primäre Lagergut handelt. Teilweise wird auf der Sohle von Gruben eine dünne verkohlte Getreideschicht beobachtet. Dieses Getreide kann durch desinfizierendes Ausbrennen der Grube vor einer Wiederverwendung derselben verkohlt und in der 


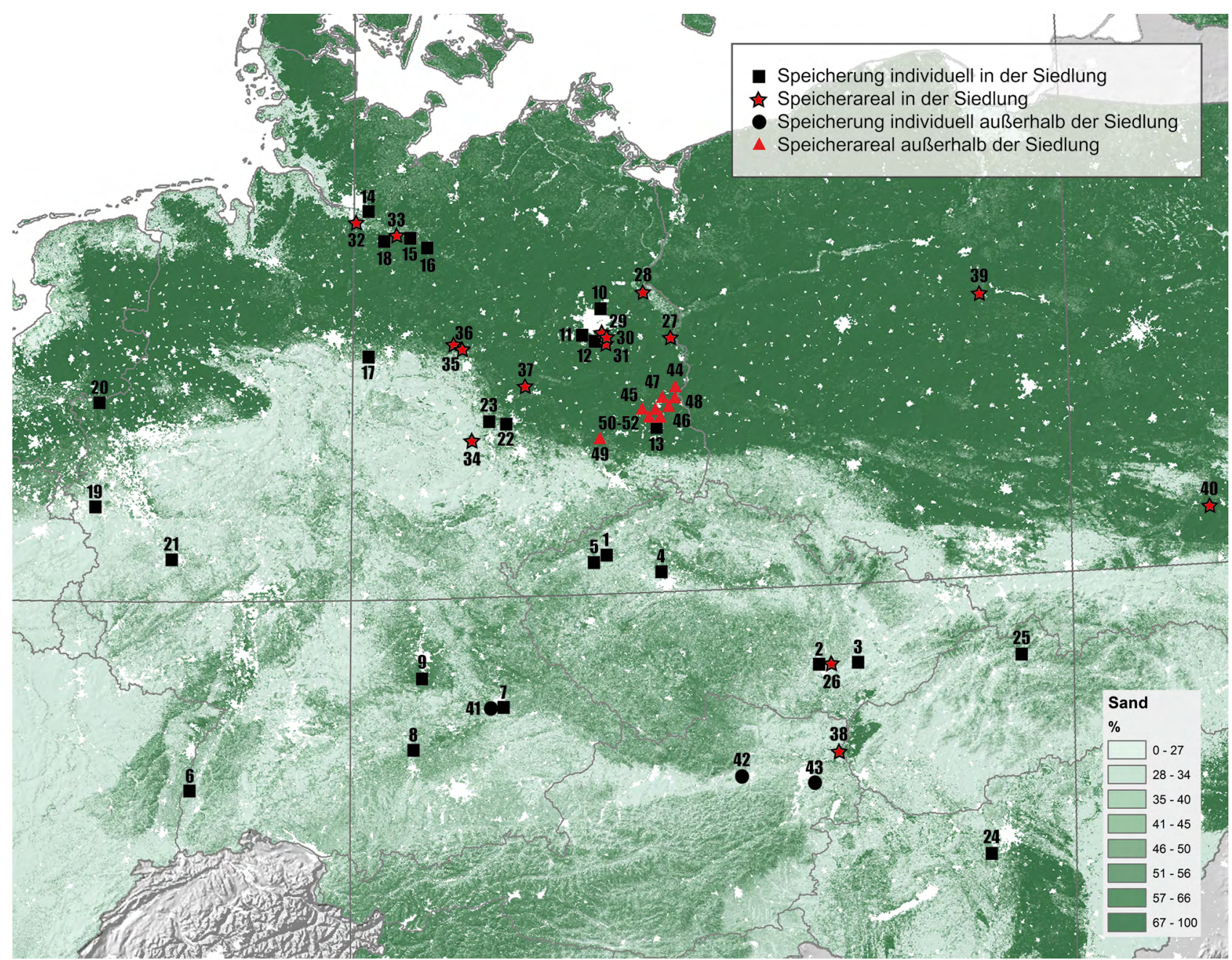

Abb. 1. Die Abbildung zeigt die im Text erwähnten Fundstellen auf einer geologischen Karte mit dem prozentualen Anteil von Sand im Boden. Die Nummern sind in einer Tabelle im Anhang aufgelistet (Kartengrundlage: European Soil Data Centre).

Grube verblieben sein. ${ }^{1}$ Auch über die Analyse von Phytoliten an bestimmten Bereichen des Befundes können Indizien auf das primär gelagerte Getreide erbracht werden. ${ }^{2}$

\section{Speichergruben - ein geniales Phänomen erfährt populä- ren Nutzen}

Im Nahen Osten bereits seit dem Epipaläolithikum bekannt, ${ }^{3}$ traten Gruben zur Bevorratung in Mitteleuropa erstmals mit der Linearbandkeramik auf ${ }^{4}$ und blieben fast

\footnotetext{
1 Willerding 1998, 18. - Den exerimentellen Nachweis dieses Vorgangs erbrachte REYNOLDs 1974, 128.

2 Balbo et al. 2015.

3 Perrot 1957, 91-110. - Perrot 1960, 14-22. - Die in der natufischen Siedlung Ain Mallaha (Eynan im heutigen Israel) entdeckten Vorratsgruben zählen zu den ältesten Nachweisen.

4 U. a. Lüning 2000. - Kempken, Oehmen 2012. -Schade-Lindig, STEINBRING 2012
}

bis in heutige Zeiten in Verwendung. ${ }^{5}$ Besonders häufig kommen Speichergruben in den für sie günstigen Phasen mit eher trockenem und warmem Klima vor. ${ }^{6}$ Es verwundert daher nicht, dass sie in der späten Bronzezeit bei idealen klimatischen Bedingungen ${ }^{7}$ gehäuft Verwendung fanden.

Die Speicherung von Lebensmitteln zählt neben dem Ausweichen auf minder präferierte Nahrung und Migration

5 In Tschechien während des 1 . Weltkriegs: u. a. Sova 1928, 121.-Im Burgenland während des 2. Weltkriegs: WALTER 1962, 47. - In Mähren, der Slowakei und Niederösterreich während des 1. und 2. Weltkriegs sowie in der Zwischenkriegszeit: Kunz 2004, 11.

6 KNörzer 1980, 452-453. - Maise 1998, bes. 218-230. - Während Speichergruben in der späten Bronzezeit sowie frühen Latènezeit teils massenhaft vorkommen, ist in dazwischenliegenden Phasen der Hallstattzeit mit feuchterem und kühlerem Klima in einigen Regionen ein deutlich verringertes Vorkommen festzustellen: WiLLERDING 1977, 371-372.

7 Willerding 1977. -Jäger, Lozek 1978. - Kossack 1995. - Maise 1998, bes. 218-224. 
zu einer der wichtigsten Strategien, um Nahrungsengpässe zu überstehen. ${ }^{8}$ Eine eigene Produktion von Nahrungsmitteln erlaubt eine zielgerechte Planung der Lagermengen und das rechtzeitige Anlegen von Speicherbehältnissen. Seit dem Neolithikum bildete neben Leguminosen wie Erbsen und Linsen vor allem das an Stärke reiche Getreide die Grundlage der pflanzlichen Ernährung. ${ }^{9}$ Die Getreidespeicherung konnte dabei auf unterschiedliche Weise sowohl unterirdisch als auch überirdisch nach zwei Prinzipien erfolgen. Die eine Möglichkeit sieht eine offene Speicheranlage vor, die idealerweise trockene, kühle und gut belüftete Bedingungen aufweist. Um eine Stockung der Klimaverhältnisse zu verhindern, wird das Lagergut häufig umgewendet. Durch künstliche Trocknung, etwa dem Rösten, kann das Getreide auch gelagert werden, ohne es regelmäßig zu wenden, es verliert durch die Hitze jedoch auch seine Keimfähigkeit. ${ }^{10}$ Demgegenüber steht die Methode, den Vorrat unterirdisch oder oberirdisch hermetisch in einem Behälter wie einer Grube oder einem Gefäß abzuschließen und im Inneren eine von der Umwelt abgetrennte Atmosphäre zu schaffen. Da Getreide ein lebender Organismus ist, der einen Atmungskreislauf besitzt, wird aus Glukose und Sauerstoff das Gas Kohlendioxid, Wasser und Energie in Form von Wärme gebildet. Gelingt es, den Behälter absolut dicht von der äußeren Umwelt abzuschließen, läuft dieser Prozess so lange ab, bis die Atmosphäre vollkommen mit Kohlendioxid gesättigt beziehungsweise der Sauerstoff verbraucht ist. In Folge gerät das Getreide in einen Zustand der Ruhe, das heißt es stoppt seine Atmung, bleibt jedoch weiterhin keimfähig. In diesem Stadium können die Körner mehrere Jahre überdauern. Während die Keimfähigkeit im Laufe der Zeit abnimmt - die Botanikerin Marianne Kohler-Schneider schätzt, dass nach zehn Jahren Speicherung nur mehr die Hälfte des Getreides keimen wird - bleiben die Feldfrüchte über mehrere Jahrzehnte genießbar, vorausgesetzt das Behältnis bleibt in Hinsicht auf eindringendes Wasser und Sauerstoff sowie austretendes Kohlendioxid dicht. ${ }^{11}$

8 BARTL 2004, 89.

9 Willerding 1998, 11. - Scheibner 2016, 110-118.

10 Zur Trocknung bzw. Darren von Getreide: Hellmund, PetzSCHMANN 2011, 191-192.

11 Mündliche Mitteilung Marianne Kohler-Schneider, Michaela Popovtschak, Ulf Baum. - ReYNolds 1974, bes. 119. - Vgl. auch antike und historische Berichte wie SCHreber 1763, 270: „dergleichen Getreyde bleibt bis 50 Jahre und mehr Jahre gut“. - Dem römischen Universalgelehrten Marcus Terentius Varro zufolge hält sich Weizen darin 50, Hirse sogar 100 Jahre: VARRo, De re rustica 1.57.2. - ZELENIN 1927, 55: „Da die Luft keinen Zutritt dazu hat, bleibt das trockne Korn in solchen Gruben sogar Jahrzehnte unversehrt; oft kommt es vor, daß Enkel zufällig das von ihren Großeltern in Gruben vergessene Getreide finden und essen“.

\section{Spätbronzezeitliche Verteilungsmuster}

Ehe begonnen wird, die strukturelle Verteilung von Speichergruben inner- und außerhalb von Siedlungen darzustellen, soll verdeutlicht werden, welche unterschiedlichen Siedlungstypen in der Spätbronzezeit zu erwarten sind. Die von Eike Gringmuth-Dallmer epochenübergreifend entworfene, funktionale Unterscheidung verschiedener Ausprägungen kann auch in diesem Fall angewandt werden. Demnach existierten landwirtschaftliche Siedlungen, die entweder autark wirtschafteten, sich also mit allem Lebensnotwendigen selbst versorgten, oder solche, die durch Tausch oder Handel mit ihrer Überschussproduktion einen Teil ihrer Lebensgrundlage erlangten. Daneben gab es wohl auch gewerbliche Siedlungen, die zumindest saisonal mit der Erzeugung von Rohstoffen sowie der Produktion von Gebrauchsgütern beschäftigt und somit in ihrer Versorgung weitgehend auf andere Siedlungen angewiesen waren. Darüber hinaus kann von Siedlungen mit einer oder mehreren überörtlichen Funktionen ausgegangen werden. Herrschaft, Schutz, Rohstoffgewinnung, Handwerk, Gewerbe, Handel oder Kult wirkten sich auf ein größeres Gebiet aus und verursachten damit eine gewisse Abhängigkeit. Im Kern größerer Gebiete standen komplexe Zentren, die alle Funktionen in sich vereinigten und eine beherrschende Rolle spielten. ${ }^{12}$

Allein diese unterschiedlichen Funktionen lassen bereits erahnen, dass Speichergruben nicht auf allen Plätzen in gleicher Weise zum Einsatz kamen. Es fällt natürlich schwer festzustellen, ob eine Siedlung oder eine politische Organisation etwa auf Landwirtschaft basierte oder ob sie durch Handel ihren Lebensunterhalt sicherte. Dies lässt sich auch nicht durch die alleinige Betrachtung der Speichergruben belegen. Sind in einer Siedlung keine unterirdischen Speicher nachweisbar, kann daraus noch nicht geschlossen werden, dass die Bewohner ihre Lebensmittel durch Handel erwarben und dementsprechend keine derart voluminösen Speicher benötigten wie eine bäuerliche Gemeinschaft. Vorräte konnten auch auf andere Art langfristig gelagert werden. ${ }^{13}$ Es sollte daher zusätzlich geprüft werden, ob der Platz für Speichergruben geeignet war. Unter anderem ist

12 Gringmuth-Dallmer 1996, 8.

13 Zur Lagerung von Getreide über einen längeren Zeitraum siehe Reynolds 1974, 124-125. - Daneben sind aus den östlichen Gebieten Europas halbeingetiefte oder ebenerdige Behältnisse mit einem Skelett aus Ästen oder Binsen bekannt, die mit einem Gemisch aus Lehm und Spreu abgedichtet wurden und ebenso hermetisch versiegelt werden konnten, um Getreide lange Zeit zu speichern: vgl. dazu Kunz 2004, 63-70 sowie Balassa, Ortutay 1982, 188: „In den Gegenden der Tiefebene, wo das Grundwasser sehr hoch stand, wurden vom Ende des 18. Jahrhunderts an überirdische Mieten aus Lehm und Schlamm gebaut, die oft 4 bis $5 \mathrm{~m}$ hoch waren und an die Rundöfen der Bauern erinnern“. 


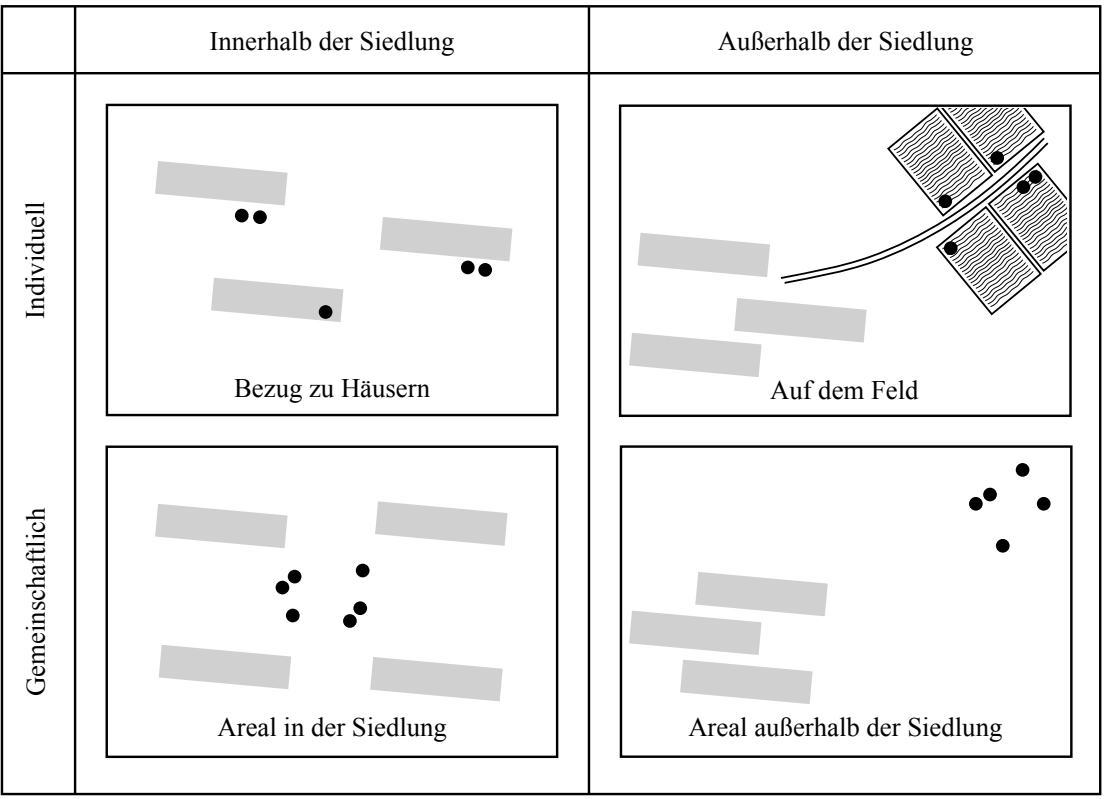

Abb. 2. Schematische Darstellung der möglichen Verteilungsmuster von Speichergruben. dabei von Bedeutung, wie hoch der Grundwasserspiegel lag und welches Bodensubstrat anstand. Relevant sind ebenso der Grad der Erosion sowie die Fläche der Ausgrabung. Wurde lediglich ein Teil der Siedlung oder die gesamte Siedlung untersucht? Befanden sich die Speichergruben womöglich in umgebenden Bereichen, die nicht erfasst wurden? Im umgekehrten Fall, also wenn viele Speichergruben aufgefunden wurden, ist mit einer bäuerlichen Präsenz zu rechnen. Treten sie in großer Zahl und großvolumig in Stätten mit überörtlicher Funktion auf, können auch Abgaben von Bauern aus der Umgebung oder ein gemeinschaftlicher Speicherplatz in Erwägung gezogen werden.

Es werden vier mögliche Speicher-Verteilungsmuster postuliert, die grafisch dargestellt werden (Abb. 2). Dabei können die Erdspeicher innerhalb und außerhalb der Siedlung individuell oder gemeinschaftlich angelegt worden sein.

\subsection{Vorratsgruben innerhalb der Siedlung}

Zunächst soll definiert werden, wie dieser Raum im Rahmen der Arbeit einzugrenzen ist. Wenn im Folgenden von „Siedlung" gesprochen wird, ist damit der Wohn- und Produktionsbereich spätbronzezeitlicher Gesellschaften gemeint. Die Begrenzung verläuft dabei nicht unmittelbar nach den äußersten Gebäuden, sondern schließt einen gewissen Bereich mit ein, der der Gesamtheit der Siedlung zuzurechnen ist. Wo dieser Bereich endet, kann nicht allgemeingültig in Zahlen ausgedrückt werden. In dieser Arbeit zählt ein Speicherareal noch zur Siedlung, wenn es den Eindruck macht, als sei es in die Siedlungsstruktur eingebunden. Dies kann auch der Fall sein, wenn es einige Meter vom Wohnareal entfernt liegt. Speichergruben, die sich mehrere hundert Meter abseits befinden, werden dagegen zum Umland gezählt.

Vorratsgruben kommen in Siedlungen in unterschiedlichen Mustern zum Vorschein. Konzentrationen treten entweder im Zentrum, randlich der Siedlung oder einige Meter entfernt davon auf. Gruben können sich auch einzeln in der Nähe oder innerhalb von Gebäuden befinden. ${ }^{14}$

\subsubsection{Vorratsgruben mit Bezug zu den Häusern}

Liegen keine eindeutigen gemeinschaftlichen Speicherareale in Siedlungen vor, weisen Siedlungspläne oft ein scheinbar unüberschaubares Gewirr an Gruben auf. Da die Raumund Funktionsstruktur bei spätbronzezeitlichen Siedlungen meist nicht unmittelbar ersichtlich ist wie etwa bei Siedlungen der Linearbandkeramik, ${ }^{15}$ kann man mit statistischen Methoden, zum Beispiel der Nächste-Nachbarn-Analyse, zu Gruppierungen gelangen, die eine nicht zufällige Anordnung der Objekte offenbaren. Diese Gruppierungen spiegeln augenscheinlich Wirtschaftseinheiten von mehrjährigem Bestand wider. Darin befinden sich meist eine bis vier Vorratsgruben sowie andere Befunde wie Öfen, Grubenhäuser und weitere kleinere und größere Gruben. Dagmar Turková und Martin Kuna vermuten, dass Gruppierungen mit einer deutlich größeren Anzahl an Objekten Ereignisse von Superpositionen verschiedener Siedlungsphasen

14 LiNdinger 2008, 42-43.

15 Boelicke 1982. - LÜNING 1991, bes. 68-69. 


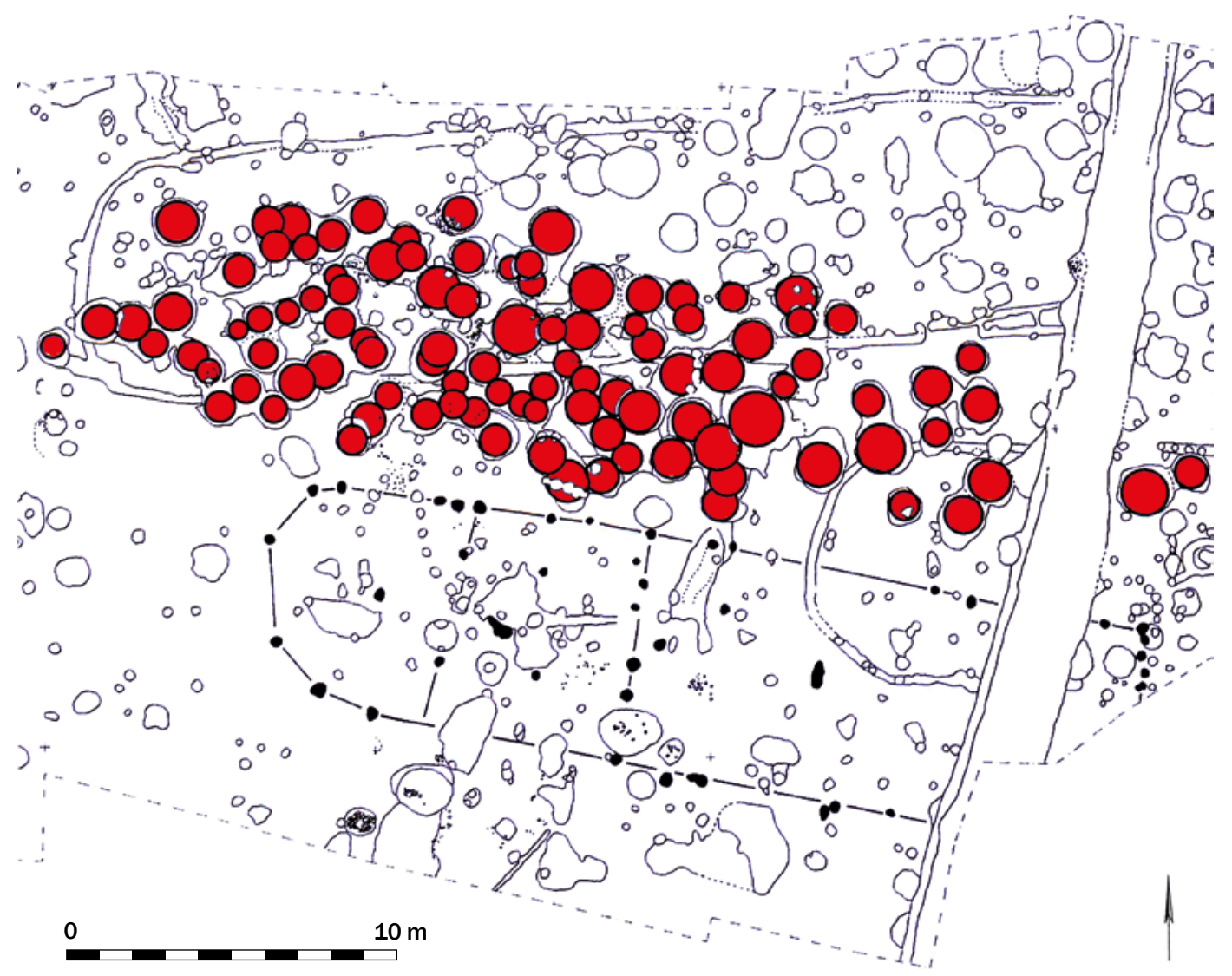

Abb. 3. Ausschnitt aus dem Siedlungsplan von Hitzacker. Die Speichergruben sind rot gefärbt (modifiziert nach Assendorp 1997, Abb. 7).

darstellen. Konstellationen mit einer geringeren Objektzahl können hingegen Überreste von Gruppierungen sein, die durch tiefen Ackerbau bereits flachere Strukturen eingebüßt haben. ${ }^{16}$

Beispiele für Siedlungen mit dieser Grubenverteilung finden sich im gesamten Untersuchungsgebiet. Sie sind in Appendix 1 aufgeführt. ${ }^{17}$ In den mährischen Fundstellen Ivanovice na Hané (3), Brno-Medlanky (2) und Březno (1) ist erkennbar, dass Speichergruben Wirtschaftseinheiten zugeordnet waren. Siedlungen wie Berlin-Buch (10), Berlin-Lichterfelde (11), Mahlow 14 (12), Pritzen 63 (13), Eschweiler-Lohn (19), Rees (20), Burgweinting (7), Erlingen (8) und Roztoky (4) weisen ebenfalls Bezüge zwischen Vorratsgruben und Wohngebäuden auf oder zeichnen sich durch mehrere kleinere Grubenkonzentrationen aus, die auf individuelle Lagerung von Lebensmitteln deuten. Obwohl oft keine Hausgrundrisse direkt nachweisbar sind,

16 Turková, Kuna 1987.

17 Die Zahlen bei den Fundorten entsprechen der Nummerierung in Appendix 1. Dort findet sich auch die jeweilige Literatur. können ihre wahrscheinlichen Standorte durch Freiflächen in Grubengruppierungen lokalisiert werden.

Die Zahl der Speichergruben je Wirtschaftseinheit hängt aber auch vom Untergrund ab. So können Gruppierungen in instabilen Sandböden aufgrund der dort deutlich kürzeren Lebensdauer der Gruben regelrechte Areale bilden. Diese wirken zwar auf den ersten Blick ähnlich wie kollektive Speicherplätze, weisen, wie sich gezeigt hat, jedoch angesichts der individuellen Nutzung andere Eigentumsverhältnisse auf. Ein gutes Beispiel ist hierbei eine Fundstelle in Hitzacker (16) (Abb. 3). Auf dem kiesig-sandigen Siedlungsareal konnten vier Hausplätze aufgedeckt werden, die, je $60 \mathrm{~m}$ voneinander entfernt, in einem Bogen um das damalige Ufer der Elbe angeordnet waren. Parallel zu den Langhäusern entstanden dicht belegte Speicherareale mit sich häufig überschneidenden Gruben. Die geradlinigen Ränder der Areale erwecken den Eindruck von ehemaligen Begrenzungen. Tatsächlich konnte in einem Fall ein vom Haus ausgehendes Wandgräbchen festgestellt werden, das wohl als Zaun für ein Grubenareal gedient hatte. In den folgenden Phasen wurde das Haus der meisten Hofplätze um 
wenige Meter versetzt errichtet. Danach benutzte man häufig die Stelle des alten Hauses als neuen Speicherplatz. Das führte dazu, dass sich die Hausgrundrisse heute stark durch Vorratsgruben gestört zeigen. Da die Gruben extrem dicht beieinander angelegt worden waren, ließ sich beobachten, dass die sekundären Verfüllungen bei jüngeren Exemplaren dunkler und humoser waren als bei älteren. Offenbar führte die auf engsten Raum gedrängte Belegung zur allmählichen Verschmutzung des Speicherareals. ${ }^{18}$

Die immense Zahl an Speichergruben, die pro Wirtschaftseinheit in einer Periode etwa 60 betrug und in der Siedlung insgesamt im vierstelligen Bereich liegen dürfte, beruht an diesem Platz einerseits auf einer über mehrere Generationen andauernden Siedlungskontinuität und andererseits auf der Kurzlebigkeit der Gruben in dem instabilen Untergrund. ${ }^{19}$

Befinden sich Vorratsgruben in der Siedlung selbst, ist häufig eine rasche sekundäre Verfüllung mit Brandschutt ${ }^{20}$ oder homogenem Material, das beim Anlegen einer neuen Grube anfiel, ${ }^{21}$ erkennbar. Auch die Seltenheit von beobachteten dünnen Einschlämmschichten und Wandverstürzen spricht gegen ein langes Offenstehen. ${ }^{22}$ Es fallen teilweise Unterschiede bei den Verfüllungen von Speichergruben innerhalb einer Siedlung auf. In Brehna (22) zeichneten sich Gruben nahe der Häuser durch eine dunklere, humose Verfüllung aus, während weiter davon entfernte Gruben kaum mit Humus versetztes, helleres Material beinhalteten. ${ }^{23}$ Offenbar wurden anfallende organische Abfälle in der Nähe der Wohnungen entsorgt. Das bedeutet, dass Verfüllungen von Vorratsgruben Hinweise auf die Siedlungsstruktur geben können, auch wenn flachere Befunde wie Hausgrundrisse nicht mehr vorhanden sind. Wurde sterile Erde eingeworfen, verdichtete sie sich nach einiger Zeit und bildete Senkungstrichter. Um die störenden Mulden zu beseitigen, verfüllte man sie mit stabilerem Material. Wie auch heutzutage beim Ausbessern von Feldwegen kamen Steine oder Keramikscherben zum Einsatz. Das erklärt die heute in vielen Gruben aufgefundenen Funde in der oberen Verfüllung, während die unteren Bereiche oft völlig fundleer sind. ${ }^{24}$ Das im oberen Teil verfüllte Material muss nicht unbedingt mit dem Alter der Grube identisch sein. Manchmal stammen

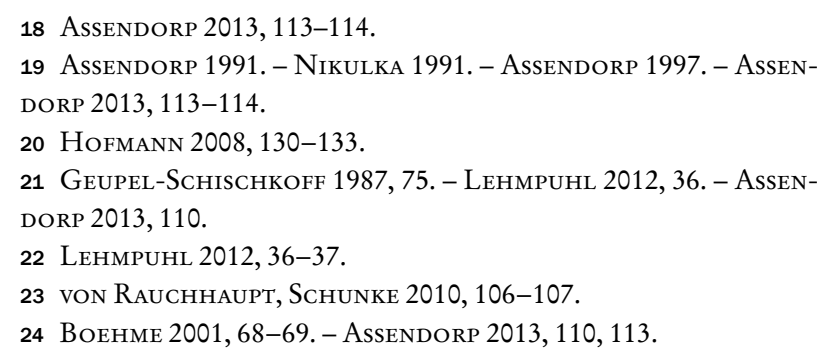

daraus verrundete und verwitterte Scherben aus älteren Belegungen der Fundstelle. ${ }^{25}$

In Bleckede-Alt Wendischthun (15) ist südlich eines Hauses eine Art freier Korridor zwischen den Speichergruben erkennbar. Dieser führt zu einem Hauseingang, der mit $2 \mathrm{~m}$ ungewöhnlich breit ist. Dem Anschein nach sollte hier der zentrale Wirtschaftseingang nicht gestört werden. ${ }^{26}$

Auch wenn, wie historische Berichte und Experimente von Peter J. Reynolds zeigen, Speichergruben oberirdisch weiterhin ohne Schaden für die Gruben begangen und befahren werden konnten, ${ }^{27}$ wurden die Siedlungen anscheinend in funktionelle Bereiche aufgeteilt. Für die individuelle Vorratshaltung wurden die Gruben in einem festgelegten Bereich nahe der Häuser gebaut. Wurden die Häuser häufig verlegt, das heißt, herrschte keine Hofplatzkontinuität vor, zeigen sich diese Siedlungen heute oft mit einem unüberschaubaren Gewirr an Gruben. Siedlungen mit beständigen Hofplätzen auf instabilen Böden weisen dagegen klar erkennbare Konzentrationen von Speichergruben auf. Diese sind jedoch keine gemeinschaftlichen Speicherareale, da hier nur derselbe Platz wieder und wieder benutzt wurde und nicht wie in den gemeinsam genutzten Plätzen gleichzeitig viele Gruben aktiv in Verwendung waren.

\subsubsection{Vorratsgruben innerhalb von Häusern}

Speichergruben konnten nicht nur neben, sondern auch innerhalb von Häusern angelegt werden (Abb. 4). Den größten Vorteil stellt dabei der Schutz gegen Witterung dar. ${ }^{28}$ Der Experimentalarchäologe Reynolds legte über mehrere Jahre Gruben auch in Häusern an und stellte fest, dass diese das Lagergut unabhängig von der Saison gut speicherten. In Jahren, in denen aufgrund starker Regenfälle Vorratsgruben im Freien versagten, konnten in Gebäuden befindliche Exemplare keimfähiges Getreide bewahren. ${ }^{29}$

Stößt man bei archäologischen Ausgrabungen auf Speichergruben innerhalb von Hausgrundrissen, werden die Gebäudestrukturen oft jünger beziehungsweise älter als die Gruben datiert. Es ist jedoch damit zu rechnen, dass

\footnotetext{
25 BÖNISCH 2006a, 314.

26 Assendorp 2013, 114.

27 Im Zuge seiner Experimente ließ er Menschen über die Gruben laufen. Sogar Traktoren mit Anhänger, die mit Tonnen von Holz beladen waren, fuhren darüber. Statt nachteiligen Effekten konnte er sogar Vorteile erkennen, da dies dazu führte, dass der Verschluss verdichtet wurde. In einem Fall war die Fläche derart verdichtet, dass eine einzelne Grube vorübergehend nicht mehr lokalisiert werden konnte: REYNOLDs 1974, 123. - Man könne über Speichergruben ,gehen, reiten und fahren“: SCHREBER 1763, 270.

28 Rosenstock 1979, 188-189.

29 Hill, Lacey, Reynolds 1983, 169-171.
} 

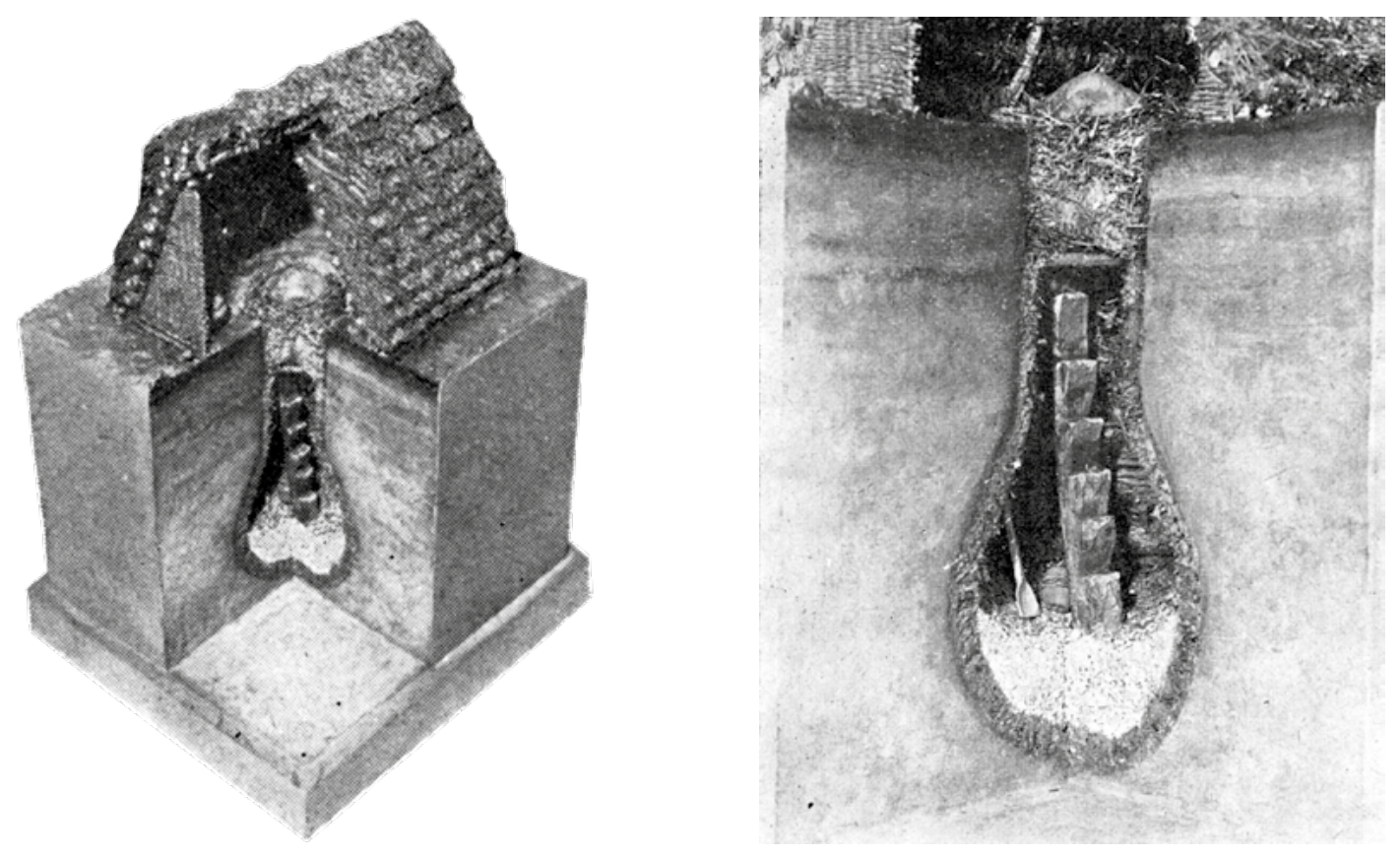

Abb. 4. Modell eines slawischen Hauses nach Befunden der Siedlung Klučov (Tschechien) mit integrierter Speichergrube (KudRnÁč 1958, Abb. 4-5).

in vielen Fällen beide gleichzeitig existierten. ${ }^{30}$ Historische Berichte belegen diese Praxis in vielen Regionen. ${ }^{31}$ Man denke vor allem an die „Traidgruben“, die bis ins 20. Jh. im Burgenland in vielen Bauernhäusern oft in einer Ecke unter einem massiven Tisch angelegt worden waren. ${ }^{32}$ Neben der Abschirmung gegen Witterung wird deutlich, dass Vorratsgruben im Haus auch mit der Absicht angelegt wurden, sie vor Fremden zu verbergen. ${ }^{33}$

Da Häuser in der Spätbronzezeit häufig keine oder nur geringe Eintiefungen in den Boden erforderten, sind ihre Standorte in den meisten Fällen nicht mehr zu eruieren. Es ist daher anzunehmen, dass die Zahl der Speichergruben in Häusern höher war, als es auf den ersten Blick erscheint.

Die genaue Funktion der Vorratsgruben, das heißt, ob in ihnen Nahrungsmittel langfristig unter Luftabschluss und

30 REYNOLDS 1974, 128.

31 KrÜNitz 1788, 661. - Suter 1964, 261. - Reynolds 1979, 79. Kunz 2004, 19, 23, 39.

32 Schmidt 1961. - Walter 1962.

33 „Da sich indessen eine solche Grube, wenn sie gleich mit Rasen dem anliegenden Boden gleich gemacht ist, arglistigen Personen von selbst verräth, indem, wenn im Sommer früh der Thau aller Orten auf dem Erdreiche verspürt wird, der Platz, so weit eine solche Grube geht, trocken ist: so wäre es am besten und sichersten, wenn man unter seinem Hause, oder von dem Keller aus, die Grube verfertigte, so würde sie auch vor den Nachbarn verborgen bleiben, und noch dazu dienen, daß man bey einem schnellen Ueberfall noch das beste dahin retten könnte“: KRÜNITZ 1788, 661.
Kohlendioxidbildung gelagert wurden, oder ob sie schlicht als „Kühlschrank“ ähnlich einem Keller fungierten, ist meist nicht mehr eindeutig festzustellen. Die dauerhafte Speicherung funktioniert nämlich auch in kleinen Gruben. ${ }^{34}$ Tendenziell deuten seichtere Vertiefungen unter einem Meter sowie nach oben nicht verengende Formen eher auf eine kurzfristigere Lagerung von Lebensmitteln wie Wurzelgemüse oder Obst hin. Es zeigt sich, dass Speichergruben sowohl in Pfostenbauten als auch in Grubenhäusern auftreten.

Eines der besten Beispiele für mögliche Vorratsgruben in spätbronzezeitlichen Pfostenbauten zeigt sich in einem Gehöft in Ochtmissen (18) (Abb. 5-6). Die Fundstelle lässt sich auf mehrere Weisen deuten. Wilhelm Gebers vermutet, dass die beiden etwa $6 \mathrm{~m}$ voneinander entfernten Hausgrundrisse unter anderem aufgrund ihrer parallelen Ausrichtung und Gleichartigkeit im Aufbau zeitgleich bestanden. Ein Feuer hätte beide Gebäude schließlich zerstört. Außerhalb der Häuser falle eine Konzentration von sechs Speichergruben auf. Da keine anderen Siedlungsspuren in unmittelbarer Nähe gefunden wurden, zu denen die Gruben gehören könnten, sei mit einem engen Kontext zum Gehöft zu rechnen. Interessant seien nun die acht größeren und kleineren Gruben innerhalb der beiden Häuser. Die meisten davon befinden sich in Haus 1 und scheinen, so Gebers, an Stellen angeordnet zu sein, die keinen störenden

34 Reynolds 1974, bes. 120-121, 127. 


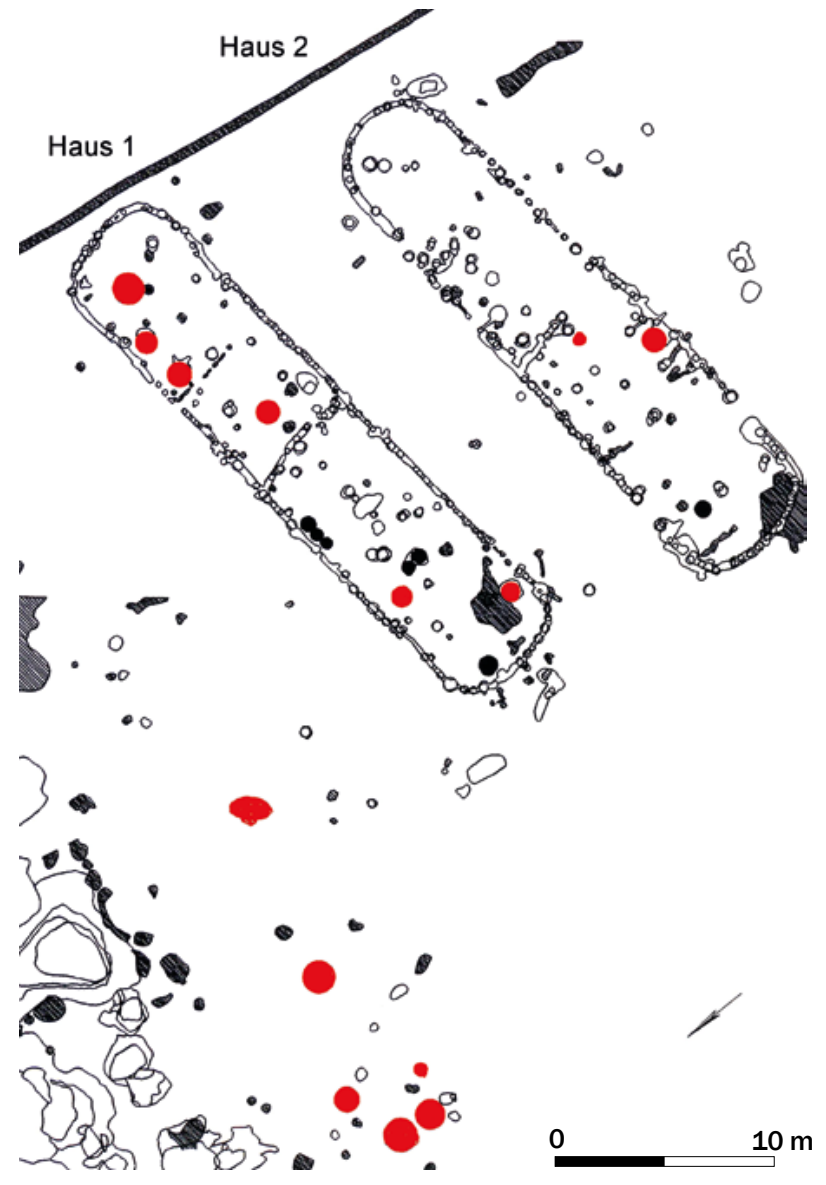

Abb. 5. Ausschnitt des Grabungsplanes von Ochtmissen mit den spätbronzezeitlichen Befunden. Die Vorratsgruben (rot) nach den Angaben des Ausgräbers W. Gebers (modifiziert nach Gebers 1997, Abb. 5).

Einfluss auf den funktionellen Innenausbau haben. Mit Ausnahme einer nicht sicher als Pfosten zu definierenden Verfärbung sei keine Überschneidung zwischen den Häusern und den Gruben ersichtlich. Aufgrund der zahlreichen Vorratsgruben, breiten Eingänge und der Innengliederung von Haus 1 mit einer weiteren Innenpfostenreihe an beiden Längsseiten, die möglicherweise ein zweites Stockwerk als Speicherebene darstellen, vermutet Gebers hier ein Speichergebäude. ${ }^{35}$ Haus 2 hingegen mit schmäleren Eingängen, einer Feuerstelle und einer anderen Innengliederung deutet er als Wohnhaus. In einem kastenförmigen, durch Pfosten markierten Innenbereich befindet sich in einer Nische eine Vorratsgrube. Es könne sich hier um einen funktional begründeten Abschnitt des Wohnhauses handeln. ${ }^{36}$

Jan Joost Assendorp bietet eine alternative Erklärung und stellt die beiden Häuser in eine Zweiphasigkeit. Seinem Modell nach wäre Haus 1 der Ursprungsbau, der in

35 Gebers 1997, 70-71.

36 Gebers 1997, 71. späterer Zeit unmittelbar daneben noch einmal erneuert wurde. Da Assendorp andere Gruben als der Ausgräber als Speichergruben interpretiert, befänden sie sich nun in zwei Arealen nördlich und südlich. Er stellt damit eine Verbindung zu den großen „Grubenwolken“, wie sie etwa in Hitzacker (16) vorkommen, her. ${ }^{37}$ Bei Assendorps Modell ist einzuwenden, dass sich die Gruben, abgesehen von dem deutlich abgrenzbaren Speicherareal nordwestlich, allesamt genau innerhalb der Häuser befanden und sich so gut wie keine Überschneidungen mit den baulichen Strukturen erkennen lassen. Wieso sollte man ein neues Haus auf einem Platz bauen, an dem sich zuvor Vorratsgruben befanden und diese genau in den Hausplan einpassen?

Nach Meinung des Autors dieses Artikels bietet sich noch eine dritte Möglichkeit an. Darin wird ebenfalls eine Zweiphasigkeit postuliert. Haus 1 bestand demnach wie in Assendorps Modell zuerst. Während dieser Zeit wurde das nordwestlich gelegene Speicherareal genutzt. Auffällig ist die ähnliche Verteilungsstruktur der Vorratsgruben wie bei den Exemplaren in den Häusern. Es kann spekuliert werden, dass hier parallel zu Haus 1 ein weiteres Bauwerk stand, das speziell für die Vorratshaltung errichtet, deshalb nicht so massiv gebaut wurde und keine Spuren im Boden hinterlassen hat. Eine einfache Konstruktion, dessen Aufgabe in erster Linie die Ableitung des Regenwassers war, hätte den Zweck erfüllt. In einer zweiten Phase entschied man sich, ein neues Wohngebäude zu errichten, Haus 2. Statt das alte Haus abzubrechen, verwendete man es weiter, um Vorräte trocken zu lagern. Das bestehende, vielleicht jedoch baufällige Dach, das man nicht mehr als Wohnung verwenden wollte, wurde als willkommener Schutz für das Speichergut gegen die Witterung genutzt.

Weitere mögliche spätbronzezeitliche Häuser mit integrierten Vorratsgruben liegen in Hamburg-Boberg (14) vor. In Haus B und D befanden sich ein beziehungsweise zwei Exemplare. ${ }^{38}$ Ebenso konnten in Wallwitz (23) Speichergruben im Zusammenhang mit Hausgrundrissen beobachtet werden. Da hier jedoch viele Gebäude von Gruben überlagert wurden, ist unklar, ob sich eingetiefte Speicher hier überhaupt im Inneren befunden haben. ${ }^{39}$ Obwohl auf dem Burgberg bei Burkheim (6) keine Häuser über Grundrisse nachweisbar sind, deutet die auffällige Südwest-NordostAusrichtung der Speichergruben auf eine planmäßige Anlage der Siedlung hin. Die Gruben waren möglicherweise im Inneren der Blockhäuser angelegt, die reihenhausartig in Zeilen errichtet wurden. ${ }^{40}$

37 Assendorp 1997, bes. 114-115.

38 SCHINDLER 1958, bes. 175-177.

39 STAhlHOFEn 1985, bes. 243.

40 Dehn 1985. - Dehn 1989. - Grimmer-Dehn ca. 1990, bes. 2-3. 


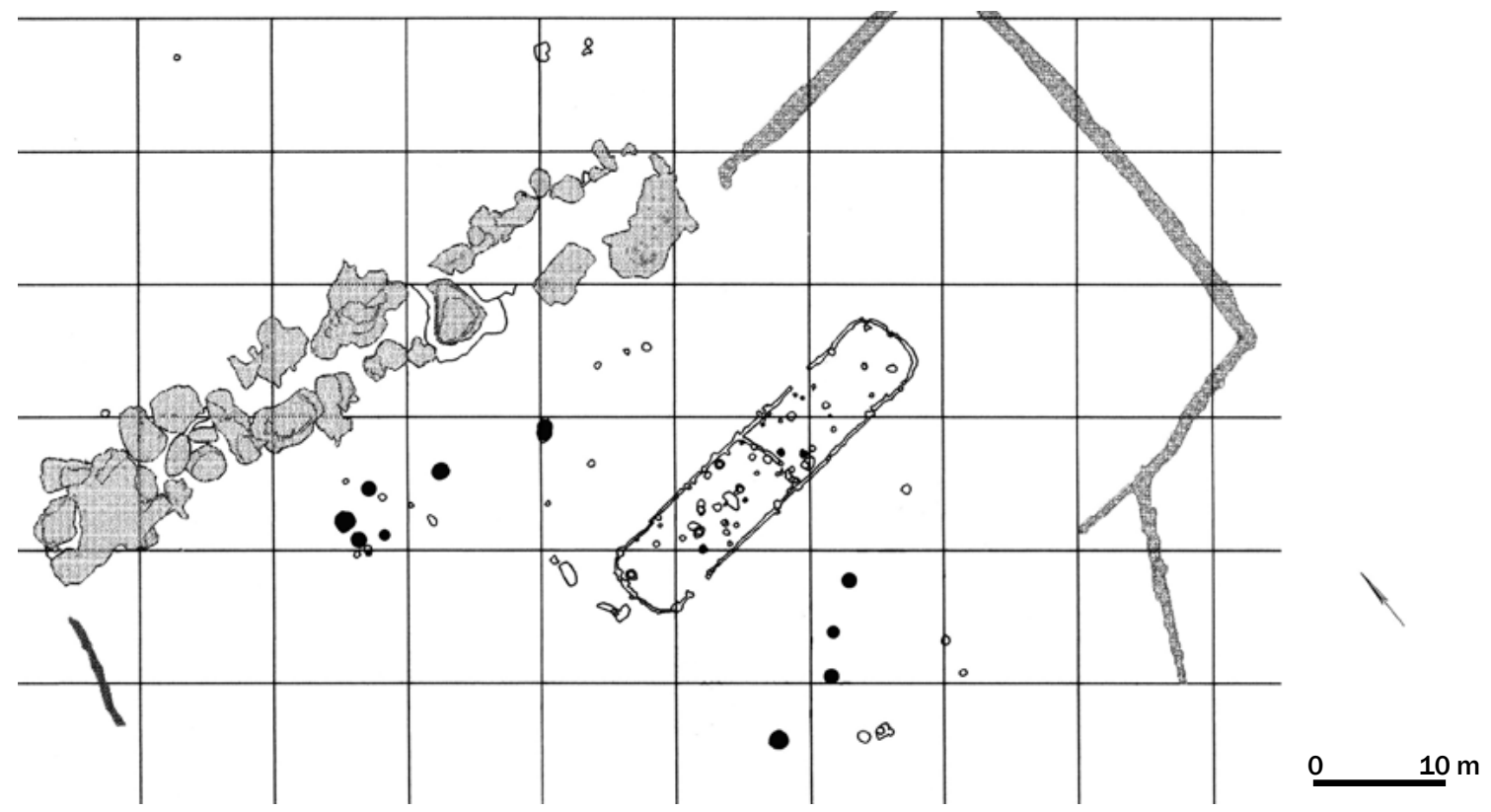

Abb. 6. Interpretation nach J. J. Assendorp. Er zeichnet im Gegensatz zu W. Gebers keine Vorratsgruben im Inneren von Haus 1 ein. Dafür finden sich nach seinem Modell vier Vorratsgruben südlich des Hauses. Dort wurde seinem Modell nach in Phase 2 Haus 2 erbaut (modifiziert nach Assendorp 2013, Abb. 6 basierend auf GeBers 1997).

Als Beispiel für mögliche Vorratsgruben in Grubenhäusern kann die eisenzeitliche Siedlung Ochtendung (21) (Abb. 7) herangezogen werden. In mehreren Grubenhäusern befanden sich kleine Gruben. In Hütte F 9 kam im Zentrum eine etwa $45 \mathrm{~cm}$ tiefe Grube mit „glockenartige[m] Umriß “41 zum Vorschein. An der Westseite der Grube war eine Art Stufe oder Nische etwa $20 \mathrm{~cm}$ tief eingearbeitet. Über und vor dieser Nische konnten noch Reste eines Holzbrettes festgestellt werden. Vier Pfosten im Inneren des Hauses bringt der Ausgräber als mögliche Konstruktionselemente mit der Grube in Zusammenhang. ${ }^{42}$

Auch in spätbronzezeitlichen Fundstellen wie Érd (24) wurden Vertiefungen im Boden der Grubenhäuser gefunden, die zur Vorratshaltung gedient haben könnten. ${ }^{43}$ Kleinere Vorratsgruben in Grubenhäusern sind in mehreren Perioden nachgewiesen ${ }^{44}$ und dienten vermutlich aufgrund ihrer Ausmaße überwiegend der kurzfristigen, kühlen Lagerung von Lebensmitteln. In einer Grube im Inneren eines jungbronzezeitlichen Hauses von Dolný KubínMedzihradné (25) gefundenen Erbsen und Pferdebohnen konnten dort verwahrt werden. ${ }^{45}$ Bei größeren Vertiefungen,

41 Tischler 1951, 60.

42 Tischler 1951 , bes. 59-61.

43 Oravecz, Mráv 2008, bes. 45 und Abb. 6.

44 In einem latènezeitlichen Grubenhaus wurde z. B. ein „,55 cm tiefer bienenkorbförmiger Keller“ gefunden: EckerLe, STOLl 1940, 20. 45 ČAPlOviČ 1975, 42-43. wie der über einen Meter tiefen Vorratsgrube eines Hauses in Vikletice (5) (Abb. 8), ist eine langfristige Lagerung mittels hermetischen Abschlusses dagegen durchaus vorstellbar. ${ }^{46}$

Dass sich Vorratsgruben sehr oft in unmittelbarer Nähe der Häuser befinden und mit ihnen in Bezug stehen oder sogar im Inneren liegen, ist über weite Zeiträume hinweg festzustellen. ${ }^{47}$ Bis in jüngste Zeit ist erkennbar, wie in manchen Orten Speichergruben untrennbar mit den Häusern verbunden waren und über Generationen vererbt wurden. In den Höfen oder Gärten konnten die Gruben mit dem wertvollen Speichergut beobachtet sowie auch versteckt werden. ${ }^{48}$

Demgegenüber steht die Vorgehensweise, Speichergruben kollektiv anzulegen, zu bewachen und im schlimmsten Fall zu verteidigen. Trotz des Wandels von individueller $\mathrm{zu}$ gemeinschaftlicher Vorratshaltung, der in der Spätbronzezeit in einigen Gebieten ersichtlich ist, blieb erstere Praktik überregional betrachtet weiterhin in vielen Gemeinschaften bestehen. Häufig zeichnen sich diese Siedlungen durch eine unregelmäßige oder verstreute Bauordnung aus.

46 Bouzek, Koutecký, Neustupný 1966, 78-81.

47 Rosenstock 1979, 188. - Vgl. auch die sogenannten Hofplätze der Linearbandkeramik: z. B. BoELICKE 1988, 328-356.

48 Kunz 2004, 76-77. 

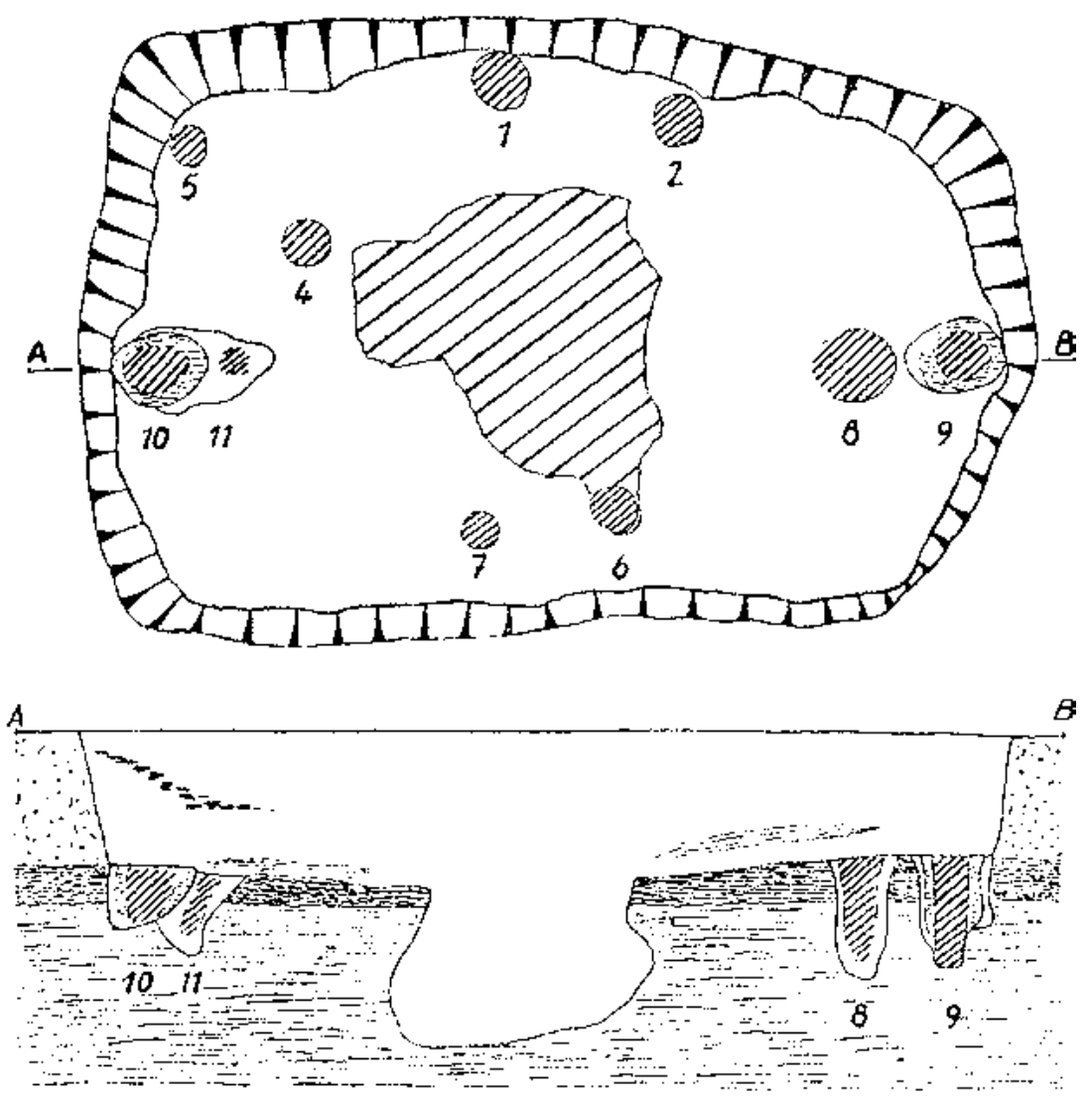

Abb. 7. Hütte F 9 der eisenzeitlichen Siedlung Ochtendung mit zentraler Vorratsgrube (Tischler 1951, Abb. 7).

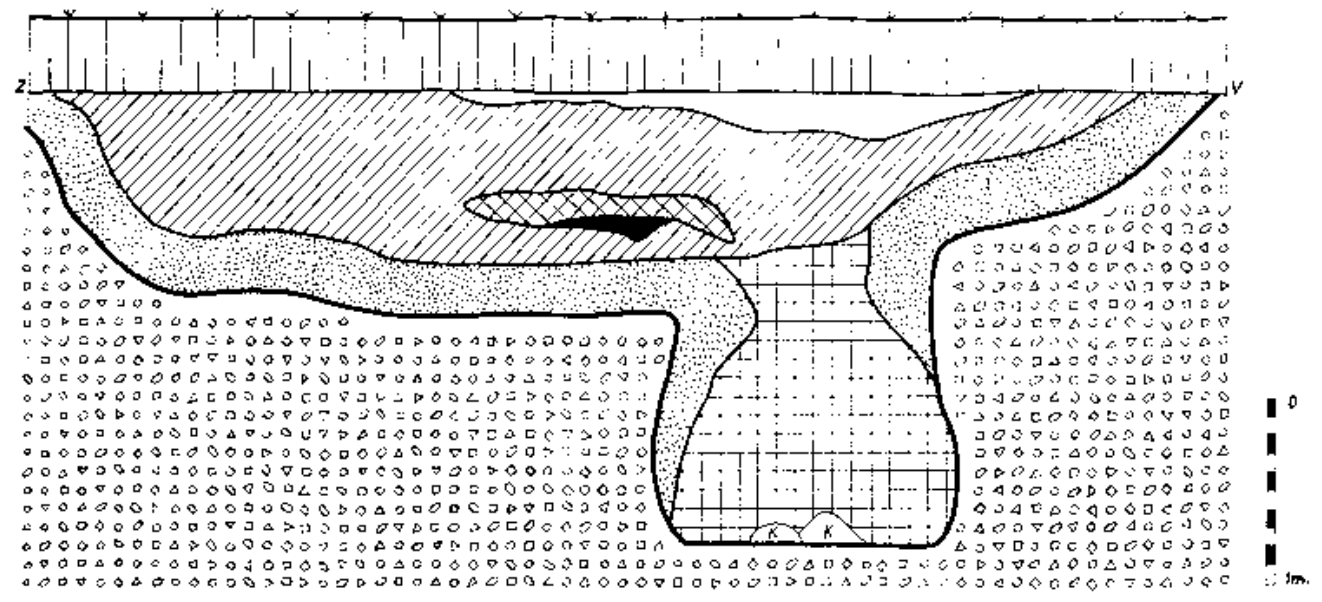

Abb. 8. Grubenhaus mit Vorratsgrube der Knovízer Kultur aus Vikletice (BouzeK, KoutecKÝ, Neustupný 1966, Abb. 27). 


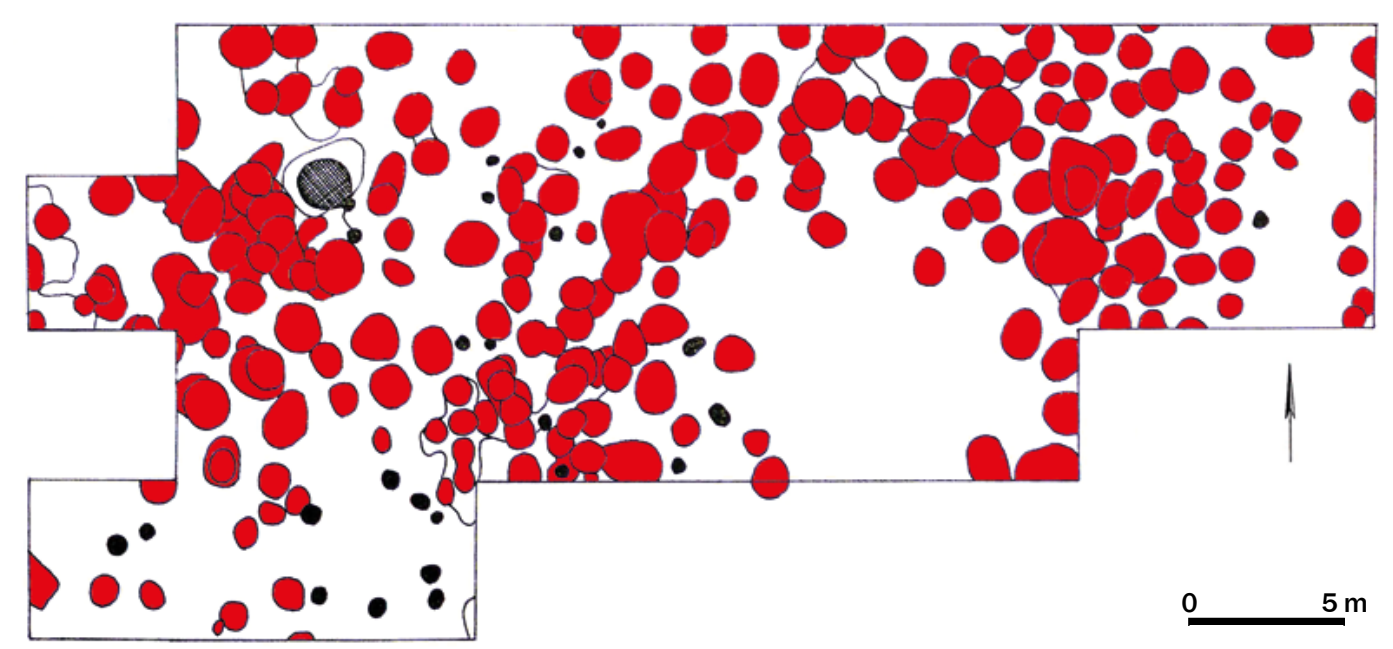

Abb. 9. Grabungsplan der Siedlung Brześć Kujawski. Die Vorratsgruben sind rot markiert (modifiziert nach KASZEWSKI 1967, Abb. 1).

\subsubsection{Speicherareale innerhalb einer Siedlung}

Speichergruben treten an manchen Orten nicht über das Siedlungsgelände verteilt, sondern konzentriert an einer Stelle auf. Das erkannten schon 1964 Jan Bouzek und Drahomír Koutecký bei einigen Knovízer Siedlungen und vermuteten eine Trennung in einen Wohn- und Speicherbereich. ${ }^{49}$ Im Unterschied zu den Grubenkonzentrationen, die sich allmählich bei individueller Vorratshaltung in der Nähe von Häusern bilden konnten, waren in diesen Arealen mehrere Speichergruben von verschiedenen Wirtschaftseinheiten gleichzeitig aktiv in Benutzung.

Diese kollektiven Speicherplätze sind zwar keine Neuheit jener Zeit, ${ }^{50}$ spiegeln jedoch in ihren Ausmaßen und dem regelhaften Vorkommen den gesellschaftlichen Wandel der Spätbronzezeit wider, der eine stärkere Gliederung mit sich bringt und unter anderem auch durch große, gut organisierte und oft befestigte Siedlungen sichtbar wird. ${ }^{51}$

Siedlungen mit gemeinschaftlich genutzten Speicherarealen weisen häufig eine regelmäßige Hausordnung auf. Die Erdspeicher konzentrieren sich dabei entweder im Zentrum oder randlich an einem speziell für die Vorratshaltung reservierten Platz. Gruppierungen im Zentrum können, müssen jedoch nicht zwangsläufig auf einem Haufen auftreten, sondern sind oft auch ringartig um einen freien

49 Bouzek, KouteckÝ 1964, 38.

50 In geringer Zahl scheinen auch schon in früheren Perioden Speicherareale zu existieren, $z$. B. auf der früh- bis mittelbronzezeitlichen befestigten Höhensiedlung Nitriansky Hrádok: Točík 1978. - Frühbronzezeitliche Siedlungen in Niederösterreich weisen häufig charakteristische kreisförmig angelegte Speicherareale auf: z. B. FüRST 2014.

51 Kossack 1995. - Heske 2010.
Platz angeordnet. Als Beispiele dienen die Siedlungen in Turbia (40) und Brześć Kujawski (39) (Abb. 9). Im Fall von Turbia gruppieren sich die Gruben um einen freien, unbebauten Platz von $30 \mathrm{~m}$ Durchmesser. Der Grubenring wird einige Male unterbrochen. Jan Michalski interpretiert diese Lücken als in verschiedene Richtungen verlaufende Straßen. ${ }^{52}$ In Brześć Kujawski sind dagegen keine Wege zu dem mit etwa $10 \mathrm{~m}$ im Durchmesser allerdings auch kleineren freien Zentrum erkennbar. Eine zweite Konzentration bildet westlich davon einen unregelmäßigen Haufen. ${ }^{53}$

Besonders gut, da großflächig gegraben, zeigt sich die Gliederung der Siedlung Haldensleben-Südhafen (35) (Abb. 10). Sie besteht aus drei Bereichen, und setzt sich aus einem Wohnareal mit mindestens acht Häusern, einem Hofplatzareal mit mindestens zwei Hofplätzen sowie einem oder vielleicht zwei getrennten Speicherarealen mit über 300 Gruben und ehemals obertägigen Speicheranlagen zusammen. Zwischen dem Speicher- und Wohnbereich befindet sich ein etwa $150 \mathrm{~m}$ breiter befundfreier Korridor. Die Fundstelle wird dennoch zur Kategorie „Speicherareal innerhalb der Siedlung“ gezählt, da das Speicherareal nach Interpretation des Verfassers dieses Beitrags Teil der Siedlung ist und nicht dem Umland zugeordnet werden sollte. Im Speicherareal wurden außerdem mehrere Feuerstellen entdeckt, die laut Ausgräber als ehemalige Kochstellen interpretiert werden können. ${ }^{54}$ Während sich die Wohnhäuser auf kiesigem Untergrund befinden, wurde der Speicherplatz in feinsandigem Boden angelegt. Bemerkenswert sind auch

52 Michalski 1986, 79.

53 Kaszewski 1967, bes. Abb. 1.

54 WAGNER et al. 2012, 71. 


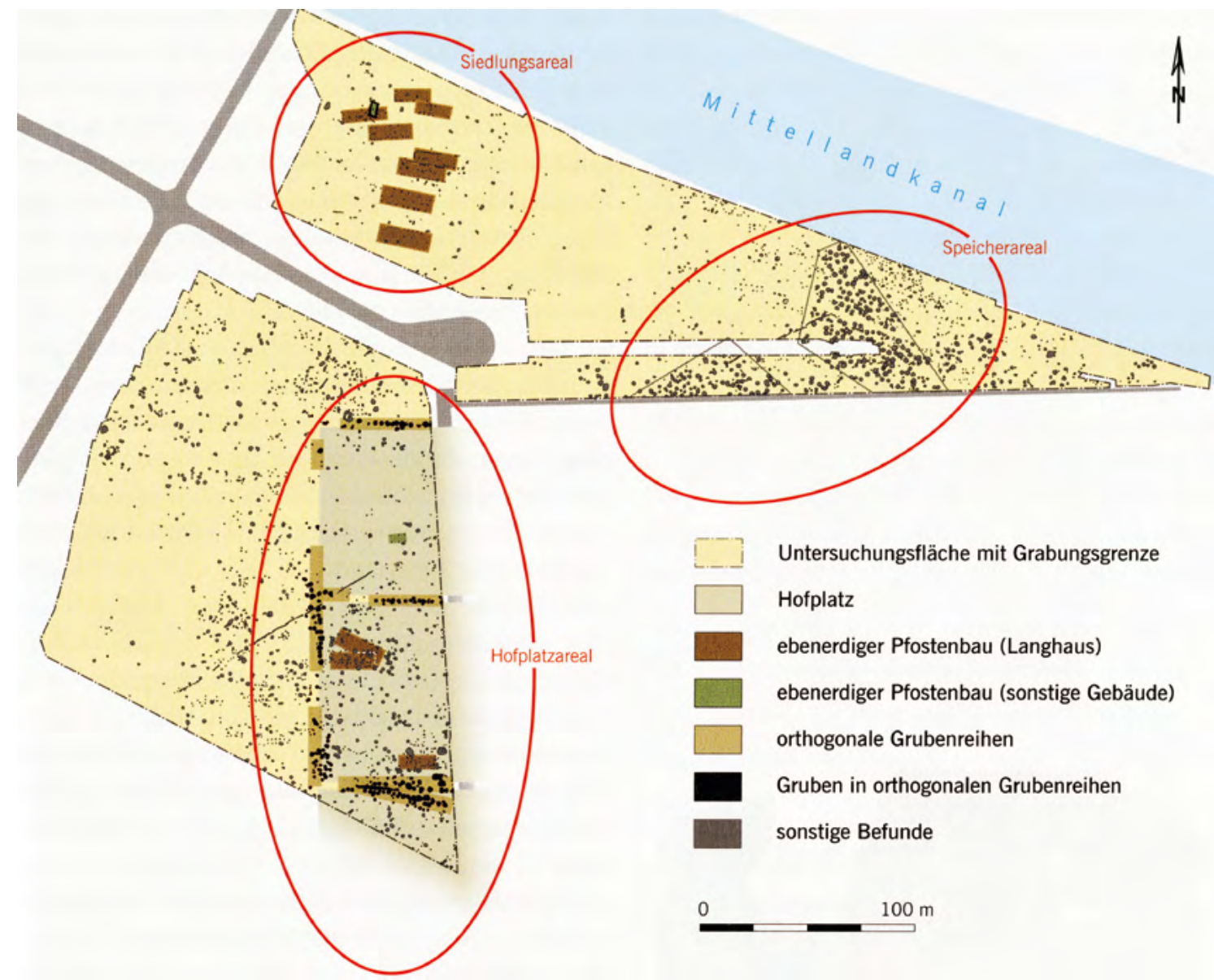

Abb. 10. Siedlungsplan von Haldensleben-Südhafen (WaGner 2014, Abb. 3).

die beiden Hofplätze, die durch sechs orthogonale, den vier Himmelsrichtungen folgende Reihen von Vorratsgruben eingefasst werden. Die Plätze mit Seitenlängen von $80 \mathrm{~m}$ und einer Innenfläche von etwa $6500 \mathrm{~m}^{2}$ ähneln früheisenzeitlichen Herrenhöfen und können mit einer zentralen Repräsentations- und Machtfunktion in Verbindung gebracht werden. Eine von Südwesten nach Nordosten verlaufende, $400 \mathrm{~m}$ lange Pfosten- beziehungsweise Grabenstruktur durchschneidet den nördlichen Hofplatz sowie den Speicherbereich. Obwohl keine datierbaren Funde der Struktur oder Überschneidungen mit Speichergruben vorliegen, ist eine Gleichzeitigkeit mit einigen Gruben aufgrund offensichtlicher gegenseitiger Bezugnahme wahrscheinlich. Sie könnte im Nordostbereich als formale oder symbolische Trennung in Wohn- und Wirtschaftsbereich fungiert haben. Der Platz befindet sich in einer intensiv besiedelten Landschaft mit mehreren Siedlungen und Gräberfeldern - teils in Sichtweite - sowie zwei Grabenwerken und einer Höhensiedlung. In der etwa $50 \mathrm{~km}^{2}$ großen Siedlungskammer nimmt Haldensleben-Südhafen eine zentrale Rolle ein und ist wohl, auch nicht zuletzt aufgrund außergewöhnlicher Funde wie einiger Geweihäxte sowie der Lage in der Kontaktzone zwischen der SaalemündungsGruppe und dem nordischen Bronzekreis, von überregionaler Bedeutung. ${ }^{55}$ Dass es in der Siedlungskammer mehrere Speicherareale gab, Haldensleben-Südhafen demnach nicht als zentraler Platz für Vorratshaltung anzusehen ist, zeigt der nur einen Kilometer östlich befindliche Fundplatz Haldensleben-Beberdüker (36) (Abb. 11). Hier konnten mehr als 2000 dicht an dicht gelegene Speichergruben entdeckt werden. Die Grenzen des Areals wurden noch nicht gefunden, weshalb mit einer noch größeren Zahl zu rechnen ist. ${ }^{56}$

In ähnlicher Form weisen auch andere Siedlungen mit zentralörtlicher Funktion wie die mehrfach gegliederte Anlage in Rathsdorf 5 (28) spezielle Speicherareale auf, die durch eine dichte Belegung mit Vorratsgruben gekennzeichnet sind. Im Fall von Rathsdorf kann durch Grabungen von etwa $10 \%$ der Anlage sowie großflächige Prospektionen unter Einsatz von Geophysik, Luftbildern und

55 WAGNER et al. 2012, bes. 70-79. - WAGNER 2014.

56 KNOLL 2012. - Wagner et al. 2012, bes. 79-81. 


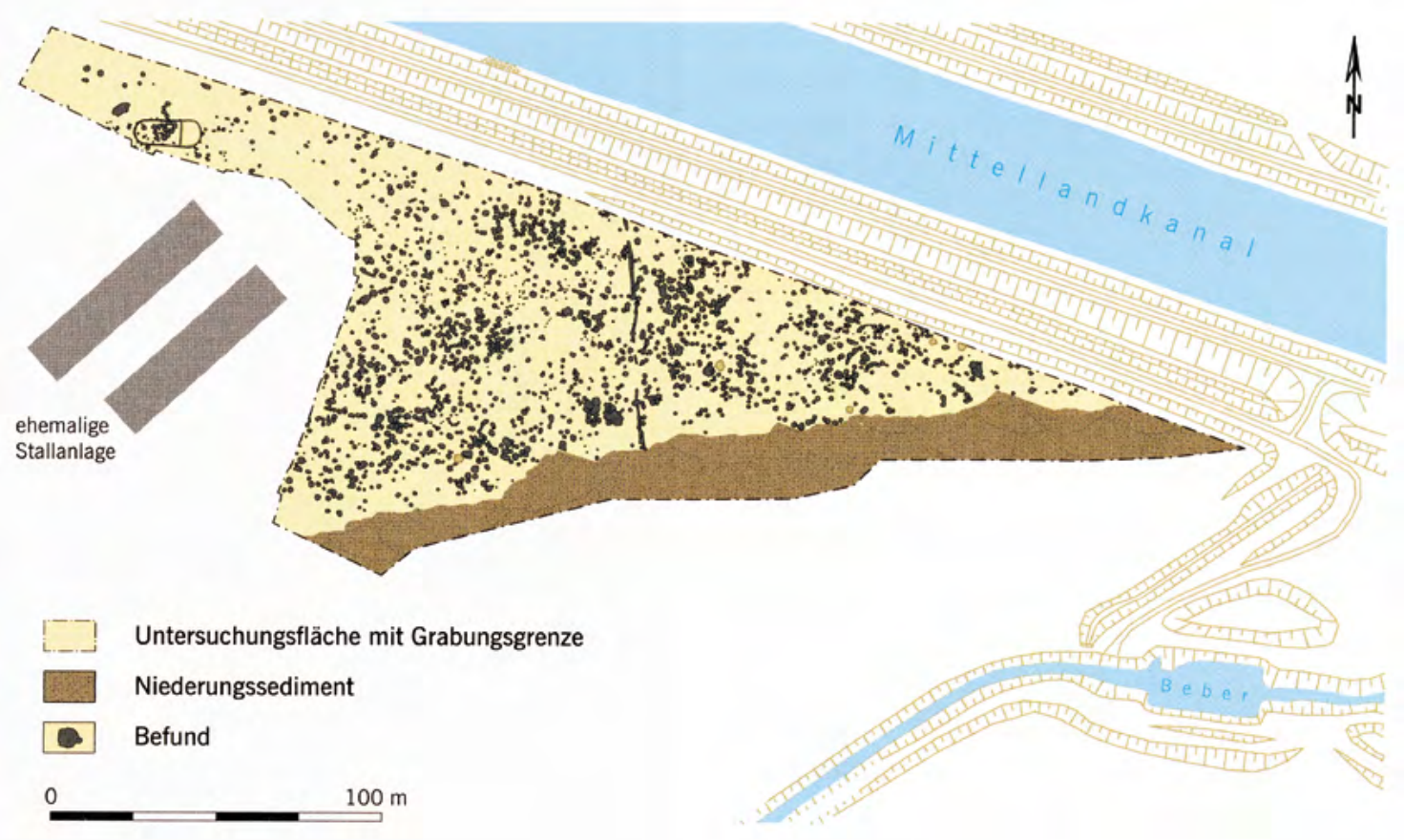

Abb. 11. Plan des Fundplatzes Haldensleben-Beberdüker mit zahlreichen Speichergruben (WAGNer et al. 2012, Abb. 18).

Feldbegehungen eine Siedlung rekonstruiert werden, die in mehrere Wohn-, Wirtschafts- und Speicherbereiche sowie ein soziales oder religiöses Zentrum gegliedert war. ${ }^{57}$

Allerdings ist erkennbar, dass es auch Zentralorte gab, in denen Vorratsgruben offenbar individuell in der Nähe der Wohnhäuser angelegt wurden. Dies wird bei der Hünenburg bei Watenstedt (17) deutlich. Hier wurden in der Unterstadt des Herrschaftssitzes Speichergruben bislang verstreut dokumentiert. ${ }^{58}$ Ein spezielles Speicherareal konnte trotz großflächiger geomagnetischer Prospektion bislang nicht entdeckt werden. ${ }^{59}$

Vermutlich waren allerdings auch in vielen Höhensiedlungen im südlichen Teil des Untersuchungsgebietes, das heißt südlich des Mittelgebirges, separate Speicherareale vorhanden. Da sich vergangene Grabungen meist auf Befestigungsanlagen konzentrierten und den Innenbereich und die Umgebung, wenn überhaupt, nur mit kleinen Schnitten untersuchten, blieben wohl viele derartige Bereiche bislang unentdeckt. Die befestigte Höhensiedlung Stillfried (38) kann in diese Kategorie fallen. Allerdings liegen hier die Gruben nicht so dicht, wie es in anderen Speicherarealen

57 Govedarica 2000. - Govedarica 2006. - Lehmpuhl 2010. NÜsSE 2012. - NÜSSE 2013. - BECKER, NÜsSE 2014.

58 Heske 2003. - Heske 2006. - HeSke 2010. - Heske et al. 2010. Heske 2016.

59 Posselt 2003. der Fall ist. ${ }^{60}$ Die dazwischenliegenden Flächen könnten auch anderen, allerdings nicht nachgewiesenen Zwecken, gedient haben. Ähnlich ist die Situation auf der befestigten Höhensiedlung Brno Obřany (26). Die Vorratsgruben können hier vor allem im Nordteil der Siedlungsfläche lokalisiert werden, während die Wohnhäuser vor allem im Zentrum und im südlichen Teil verortet waren. ${ }^{61}$ Anzumerken ist in diesen und anderen ähnlichen Fällen im südlichen Mitteleuropa, dass der Untergrund hier aus standfestem Löß besteht. Die Speichergruben besaßen demnach eine sehr viel längere „Lebensdauer“ als Exemplare aus norddeutschen Sandgebieten. Das Fehlen der Notwendigkeit, sehr häufig neue Erdspeicher zu bauen, könnte der dortigen Bevölkerung die Möglichkeit gegeben haben, ihr Speicherareal in einer lockereren Streuung und vielleicht unter anderen Gesichtspunkten anzulegen.

Weitere Siedlungen unterschiedlichen Charakters mit Speicherarealen sind Esperstedt (34), ${ }^{62}$ Zieko (37), ${ }^{63}$

60 Hellerschmid 2006. - Benedikt Biederer und Monika Griebl bereiten eine Monografie zum Thema „Die Speichergruben der späturnenfelderzeitlichen Wallanlage von Stillfried an der March“ vor.

61 АDÁмEK 1961, 198.

62 Die grabenumwehrte Flachlandsiedlung wurde im zentralen Bereich intensiv für Vorratshaltung genutzt: GLASER, DöHLE 2006. 63 Das Speicherareal befand sich auf dem höchsten Punkt der Geländekuppe: GansLmeier 2004. 
Waltersdorf 10 und 11 (29, 30), ${ }^{64}$ Frankfurt (Oder) (27), ${ }^{65}$ Zeuthen (31) ${ }^{66}$ und Rullstorf (33). ${ }^{67}$ Auch in Hittfeld (32) konnten auf einer Geländekuppe etwa 160 (insgesamt wohl 300 bis 400) dicht beieinanderliegende Vorratsgruben ausgegraben werden. Die Gruben wiesen unterschiedliche Dimensionen und Formen von flach bis tief und zylindrisch bis kegelstumpfförmig auf. Das Speicherareal befindet sich östlich der Wohnhäuser. Mit zunehmender Entfernung von den Gebäuden nahm die Funddichte ab und die Grubentiefe $\mathrm{zu}^{68}$

Gesamt betrachtet ergibt sich ein Bild, wonach vor allem größere, oft befestigte und streng organisierte Siedlungen teils mit zentralörtlicher Funktion ein oder mehrere Speicherareale in bestimmten Bereichen ausbildeten. Eindeutig nachzuweisen sind sie vor allem nördlich der Mittelgebirgszone. Da südlicher häufig standfestere Böden für Erdspeicherung gewählt werden konnten, sind hier womöglich kleinere Areale mit lockerer Streuung der Gruben zu erwarten.

Der Blick über das Untersuchungsgebiet hinaus lässt erahnen, dass auch in anderen Siedlungen dieser Zeit gemeinschaftliche Vorratsspeicherung betrieben wurde. Etwa in Mittelmeerländern konnten kleinere und größere Konzentrationen von in Fels gearbeiteten Vorratsgruben gefunden

64 Auf dem Fundplatz Waltersdorf 10 grenzt eine Pfostenreihe, womöglich ein Zaun, das Speicherareal ab. Auf dem Fundplatz Waltersdorf 11 dient ein Graben als Grenze des Speicherplatzes: STARK 2006, 67.

65 Das aus über 1000 Gruben bestehende Speicherareal war vom Wohnbereich abgetrennt; 50 Kochgruben befanden sich im nördlichen Bereich. Die Fundstelle wird ebenso wie Haldensleben-Südhafen in die Kategorie „Speicherareal innerhalb der Siedlung" gestellt, da die Speicher eher der Siedlung als dem Umland zuzuweisen sind: Hummel, Soeters 1999.

66 Der Speicherplatz befand sich wahrscheinlich nördlich der Wohnbauten. Pfostenspuren deuten auf eine mögliche Einhegung des Areals hin: Schlegel, Wiegert 2006.

67 Die mehr als 120 Speichergruben konzentrieren sich in einem schmalen Mittelstreifen in der Siedlung in lockerem, feinem Sand. Tonige Bereiche werden dagegen ausgespart. Eine Grube enthielt verkohlten, fast reinen Saathafer, der von Gebers als Primärbefund gedeutet wird. Allerdings kann es sich auch um sekundär verfüllten Abfall handeln. Im südlichen Bereich befanden sich außerdem zwei Mehrzwecköfen. Nach Interpretation von Gebers dienten sie der Trocknung des Getreides vor der Lagerung: Gebers 1985. - GEBERs 2004. - Gebers 2009. - Reynolds hält das Dörren von Getreide dagegen für kontraproduktiv, da der Atmungskreislauf der Körner zerstört wird und somit kein Kohlendioxid mehr gebildet werden kann. Wahrscheinlicher sei, dass die Öfen für das Dörren nach der Speicherung eingesetzt wurden: ReYNolds 1974, 126. - REYNOLDS 1988, 26.

68 Sielmann 1974. werden, die sich entweder neben oder in einem bestimmten Bereich der Siedlung befunden haben. ${ }^{69}$

\subsection{Vorratsgruben außerhalb der Siedlung}

Speichergruben lagen aber nicht immer innerhalb von Siedlungen. Es ist zu beobachten, dass sie auch in anderen Zeitepochen häufig in unmittelbarer Nähe oder auch in weiterer Entfernung zur Ortschaft angelegt wurden. ${ }^{70}$ Davon zeugen unter anderem Schriftquellen der letzten Jahrhunderte. Ebenso wie innerhalb der Siedlung wurden Speichergruben außerhalb sowohl kollektiv in sogenannten Speicherarealen als auch individuell auf dem eigenen Acker angelegt. Als Sonderform sind reihenförmige Anlagen von Gruben entlang von Wegen zu beobachten. ${ }^{71}$

Die Entscheidung, Speichergruben nicht im Schutze der Siedlung anzulegen, konnte unterschiedliche Ursachen haben. So konnte etwa der Standort gewählt werden, weil die Umweltbedingungen für die unterirdische Lagerung besser als im Ort selbst waren. Ein hoher Grundwasserspiegel oder ungeeignetes Bodensubstrat waren oft ausschlaggebende Faktoren. Daneben könnte auch bewusst ein Platz gesucht worden sein, an dem die Speichergrube noch besser zu verstecken war als im direkten Umfeld des Hauses. ${ }^{72}$ Wohl auch zur Reduzierung des Arbeitsaufwandes legten manche die Gruben direkt an dem Platz an, an dem das Getreide ausgedroschen wurde. Dieser befand sich häufig neben den Äckern. ${ }^{73}$ Ein weiterer Grund dafür könnte das Ausbrennen der Gruben sein. Die oft tagelang anhaltenden Feuer zur Trocknung, Desinfizierung und Härtung der Gruben waren nicht nur für angrenzende Gebäude gefährlich, sondern der Rauch schädigte auch Tiere und Menschen. Deshalb war es manchmal erwünscht, die Speichergruben außerhalb der Ortschaft anzulegen. ${ }^{74}$ Hierbei wurden wahrscheinlich Stellen gewählt, die entgegen der Hauptwindrichtung lagen.

\subsubsection{Vorratsgruben auf dem Feld oder entlang von Wegen}

Wie bereits erwähnt, sprechen mehrere historische Berichte von Speichergruben, die auf den eigenen Äckern angelegt wurden. Ähnlich wie Gruben direkt bei den Wohnhäusern

69 Auf dem höchsten Punkt der spanischen Siedlung As Laias wurden zahlreiche Vorratsgruben in den Felsen gearbeitet: Tereso et al. 2013. - Neben der maltesischen Siedlung il-Qlejgha tal-Bahrija wurde eine Konzentration von Vorratsgruben gefunden: CARDONA, Zамміт 2015.

70 BARTL 2004, 543.

71 Z. B. Kunz 2004, 19, 23, 36, 41, 44-45, 79.

72 Z. B. vON BRAND 1702, 144.

73 Anonymus 1772, 213.

74 Ein ungarisches Verbot aus dem 18. Jh. sollte Speichergruben aus den Städten verbannen, da die Feuer regelmäßig Verletzungen bei Tieren und Menschen verursachten: Kunz 2004, 79. 
zeugen diese von individueller Speicherung. Im Hinblick auf spätbronzezeitliche Gesellschaften ist ein Nachweis einer solchen Vorgehensweise schwierig. Zum einen ist heute meist unbekannt, wo sich die Äcker befanden, wo deren Grenzen verliefen und wem sie gehörten. Zum anderen sind die dortigen Speichergruben erheblich schwerer zu entdecken als solche in Siedlungen beziehungsweise in großen Speicherarealen. Es ist damit zu rechnen, dass die Zahl von Fundstellen mit potentieller Vorratshaltung auf dem Feld deutlich unterrepräsentiert ist. Nur großflächige Grabungen, die auch das Umland von Siedlungen miteinschließen, können solche Nachweise erbringen. Bislang sind lediglich Zufallsentdeckungen von Speichergruben getätigt worden, die einzeln und fernab von sonstigen Befunden lagen.

Möglicherweise ist die Fundstelle von Hafnerbach (42) in einen solchen Kontext einzureihen. Hier wurden in einem $10 \mathrm{~m}$ breiten Streifen zwei urnenfelderzeitliche Gruben entdeckt. Während die nördliche Grube einen kreisförmigen Grundriss und kegelstumpfförmige Gestalt aufwies, unterschied sich die zweite durch ein ovales Planum und zylindrische Form. Die in Ausmaßen und Datierung ähnlichen Gruben befanden sich etwa 20 m voneinander entfernt und könnten zeitgleich zwei unterschiedliche Funktionen erfüllt haben. Es wurden keine weiteren Befunde entdeckt. Anzumerken ist jedoch, dass weitere Strukturen wie Pfostenlöcher bereits abgetragen worden sein könnten. ${ }^{75}$

Außerhalb einer Siedlung und nicht im Kontext zu einem Friedhof wurden zwei nebeneinander gelegene mittelbis spätbronzezeitlich datierende Gruben bei Sinzing (41) dokumentiert. Aufsehen erregten besonders die wahrscheinlich deponierten Gefäße sowie verkohlte, geschälte Eicheln und Ackerbohnen. Der angenommene kultische Hintergrund $^{76}$ könnte jedoch eine sekundäre Maßnahme darstellen. Vielleicht dienten die Gruben zuvor als Speicher für Feldfrüchte.

Ähnlich zeigt sich die Situation in Wien-Unterlaa (43) (Abb. 12). Auf einer größeren Fläche kamen lediglich drei isoliert gelegene urnenfelderzeitliche, kegelstumpfförmige Gruben zu Tage. Auch aufgrund des geringen Siedlungsabfalls nimmt der Bearbeiter Martin Penz an, dass das Areal nicht als Siedlung im engeren Sinn zu verstehen ist, sondern als "landwirtschaftlich genutztes Umland im Nahbereich der eigentlichen Wohnstätten “.77 Die dazugehörige Wohnstätte könnte ein etwa $650 \mathrm{~m}$ entferntes, ähnlich datierendes Gehöft mit zwei größeren Pfostenbauten und sechs Vorratsgruben sein. ${ }^{78}$

75 GÖller 1996.

76 Petrosino, Putz 2003.

77 SAmonig 2002. - Penz 2011, bes. 186-190.

78 Huber, Traunmüller, Haunschmid 2005.

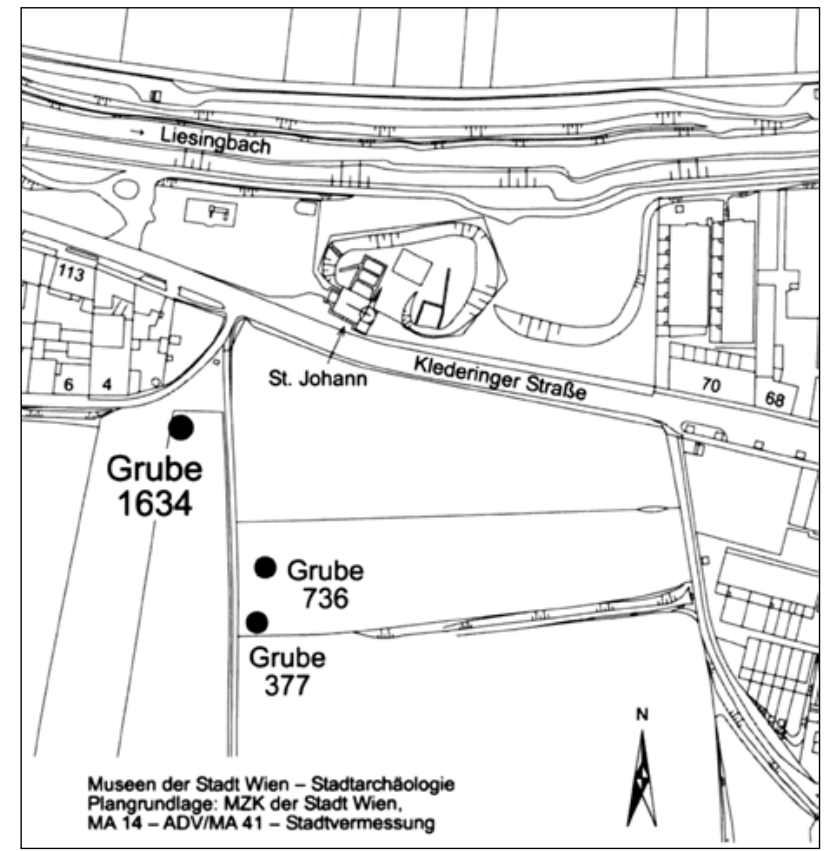

Abb. 12. Lage der urnenfelderzeitlichen Gruben in Wien-Unterlaa (Penz 2011, Abb. 1).

Wie auch Speichergruben im Feld sind solche entlang von Wegen heute nur schwer nachzuweisen. Eine oder noch besser zwei parallele Reihen von Gruben ohne sonstige Siedlungsbefunde könnten darauf hinweisen. Bislang sind derartige Fundstellen aus der Urgeschichte kaum bekannt. Aus modernen Zeiten ist dagegen häufiger überliefert, dass Gruben zur Bevorratung der Lebensmittel entlang von Wegen angelegt wurden. ${ }^{79}$ Diese Anlagen wurden auch kollektiv von den Gemeinschaften genutzt.

\subsubsection{Speicherareale außerhalb der Siedlung}

In der Spätbronzezeit ist das Phänomen der Speicherareale abseits von Siedlungen vor allem aus der Lausitz bekannt. Die aufgrund von Braunkohleabbau großflächig geöffneten Flächen bieten vor allem seit dem Einsatz moderner Technik ab 1990 dort die Chance, ganze Siedlungsgebiete archäologisch zu untersuchen. Die meist nur aus steil-kegelstumpfförmigen oder zylindrischen Gruben bestehenden Flächen können dort neben Siedlungen und Gräberfeldern als eigenständige Fundplatzgattungen gewertet werden. Die Zahl der Gruben bewegt sich meist im dreistelligen Bereich, wobei nur wenige Areale vollständig ausgegraben

79 Schмidт 1961, 145 zufolge stand eine Reihe von Fruchtspeichern am Westrand des Weges von der Bahnstation Unterpetersdorf, Burgenland, in die Ortschaft noch Mitte des 20. Jhs. in Verwendung. Beim Straßenbau in Kovalov nahe Senica (Slowakei) wurden 196232 Speichergruben gefunden, die wohl um 1900 auf beiden Seiten eines Weges angelegt worden waren: Kunz 2004, 44. 


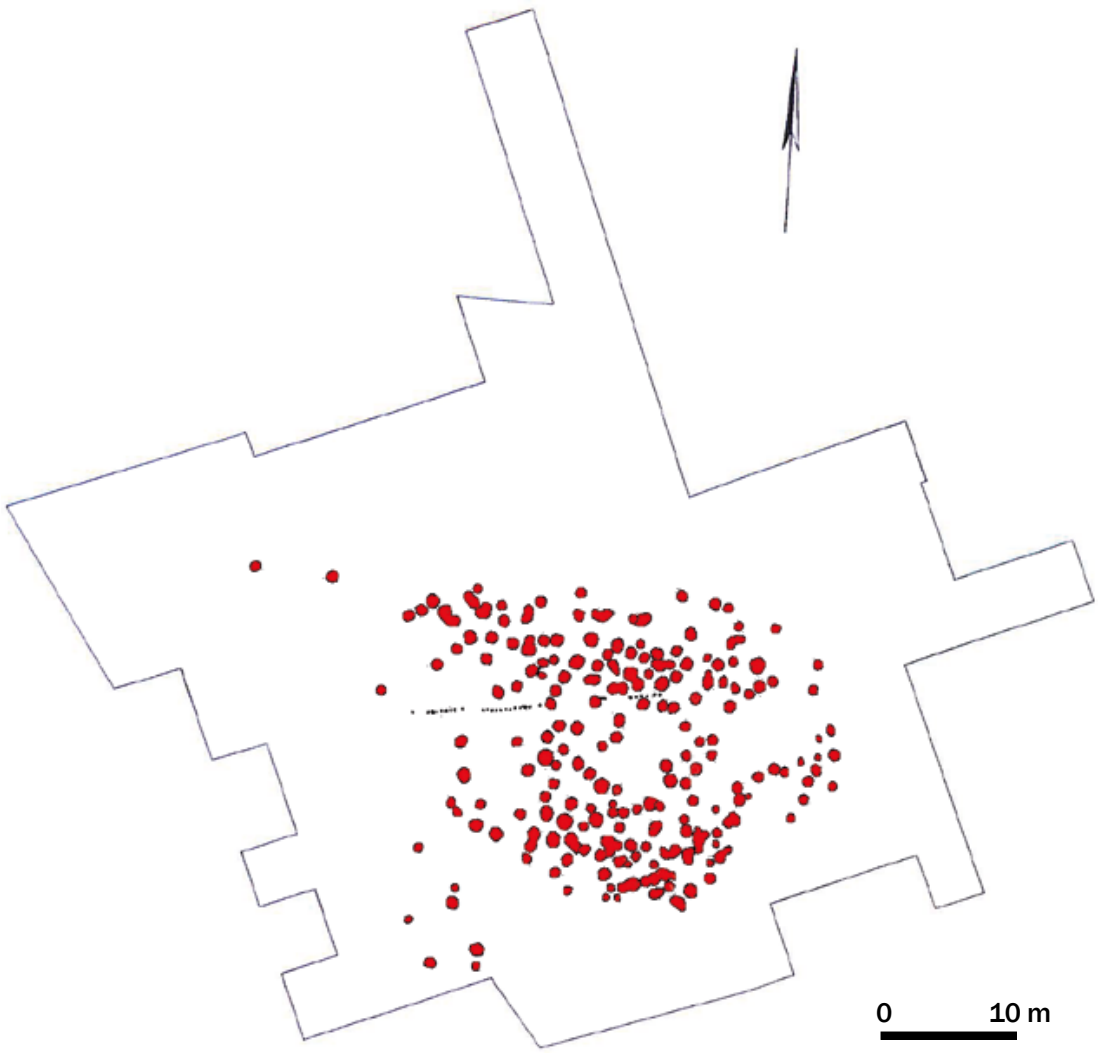

Abb. 13. Plan des Speicherareals Groß Lieskow 203 (modifziert nach PASDA 2002, Abb. 6). wurden. ${ }^{80}$ Als sichere Vertreter dieser Gattung zählen Groß Lieskow 203 (46) (Abb. 13), Heinersbrück 45 (47) (Abb. 14) und Horno 32 (48) (Abb. 15). ${ }^{81}$

Daneben ist eine Vielzahl weiterer Plätze bekannt, die als ehemalige Speicherareale deutbar sind. Etwa Pritzen 23, 27 und 61 (50-52), Grießen 1 (44), Groß Jauer 8 (45) und Merzdorf 33 (49) weisen ebenfalls als einzige Befundgattung derselben Zeitstellung Speichergruben auf. ${ }^{82}$ Allerdings sind hier nur kleinere Flächen untersucht worden, oder die Gruben liegen in einer lockereren Streuung vor. An diesen Plätzen ist es auch möglich, dass seichtere Siedlungsbefunde bereits erodiert sind. Für eine Deutung als abseits gelegene Speicherareale spricht das geringe Fundaufkommen in den Gruben. Aus gesicherten Kontexten ist nachgewiesen, dass die Fundmengen mit Entfernung zum Gehöft deutlich abnehmen. ${ }^{83}$

Die separaten Speicherareale liegen häufig auf Kuppen, Hängen kleiner Erhebungen oder Binnendünen. Teils sind dies Stellen, die offenbar nicht anderweitig nutzbar waren. ${ }^{84}$

80 BÖNISCH 1989. - BÖNISCH 1996, bes. 85-86. - BÖNISCH 2004. BÖNIsCH 2006a.

81 Siehe auch BöNISCH 2006a, bes. Abb. 7-8.

82 Siehe auch BÖNIsch 2006a, bes. Abb. 6.

83 BÖNISCH 2004, 96.

84 BÖNISCH 2006a, 316-320.
Die häufige Platzwahl oberhalb der Häuser sollte außerdem eine trockene Speicherung garantieren. ${ }^{85}$ Bestätigt wird das durch Zahlen, wonach Speicherareale eine durchschnittlich größere Entfernung zum Grundwasser aufweisen als zeitgleiche Siedlungsstellen. ${ }^{86}$ Ausnahmen, wie die Position des doppelten Speicherareals Horno 32 (48) (Abb. 15 und 16) in einer Erosionskerbe, ${ }^{87}$ entstanden vermutlich durch die bessere Sicht von den beiden zugehörigen Wohnhäusern auf die Stelle.

Aufgrund der großflächigen Untersuchungen im Umfeld von Horno 32 (48) sind die zwei Gehöfte mit großer Wahrscheinlichkeit beide dem Speicherplatz zuzuordnen, da keine weiteren Strukturen mit ähnlicher Zeitstellung festgestellt werden konnten. Auffällig ist in diesem Fall die Zweiteilung des Speicherareals in je eine etwa gleich große Ost- und Westhälfte mit 90 beziehungsweise 111 Gruben. Offenbar teilten beide Gehöfte den 280 beziehungsweise $340 \mathrm{~m}$ entfernten Speicherplatz, wobei beide innerhalb des Areals einen eigenen Bereich nutzten. ${ }^{88}$ Diese Entfernungen von etwa $300 \mathrm{~m}$ zwischen Wohnplatz und Speicher sind repräsentativ für die Niederlausitz. Zwar kann meist nicht mit

85 BÖNISCH 2004, 96.

86 BÖNISCH 1996, 130.

87 BÖNISCH 2003. - BÖNISCH 2006a, bes. Abb. 8.

88 BÖNISCH 2004, 96. 


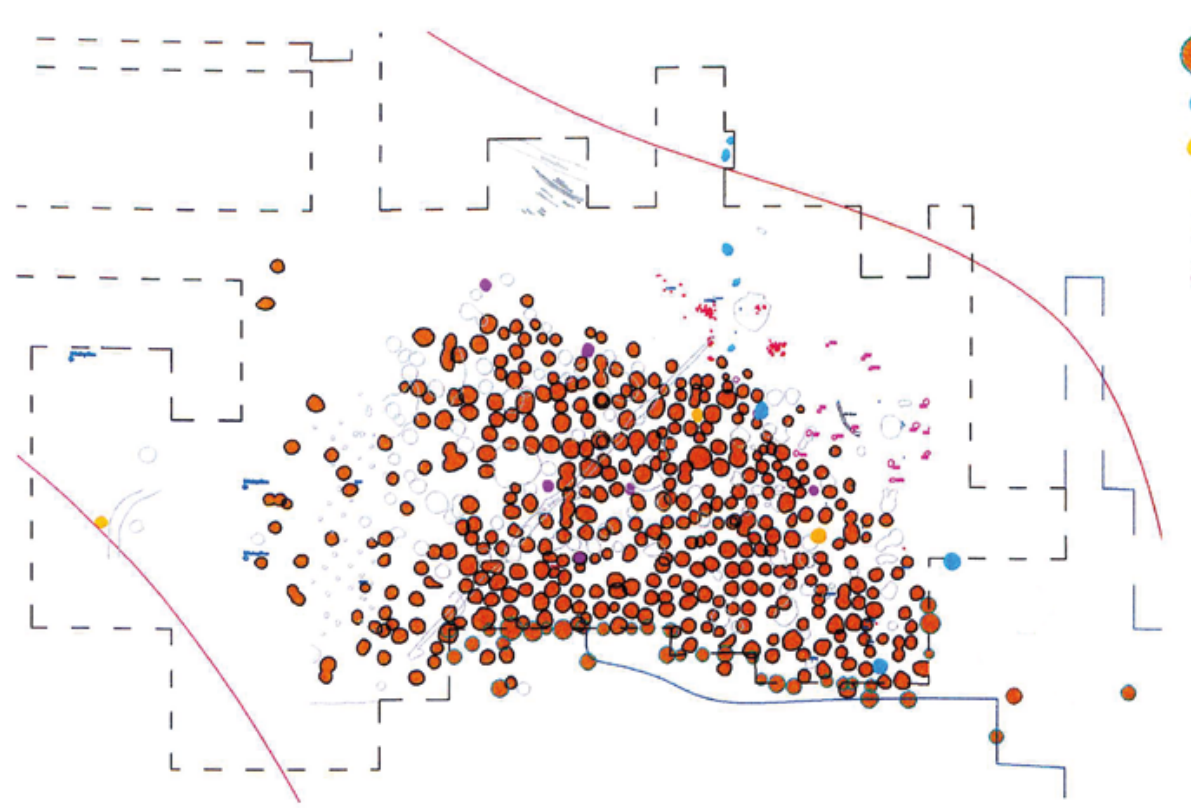

bronzezeitliche Gruben

- Gruben, Zeitstellung unklar

- Silex

, Keramik

- Pfosten?

○ unsichere Gruben

Abb. 14. Plan des Speicherareals Heinersbrück 45 (modifiziert nach UHL 2003, Abb. 36).

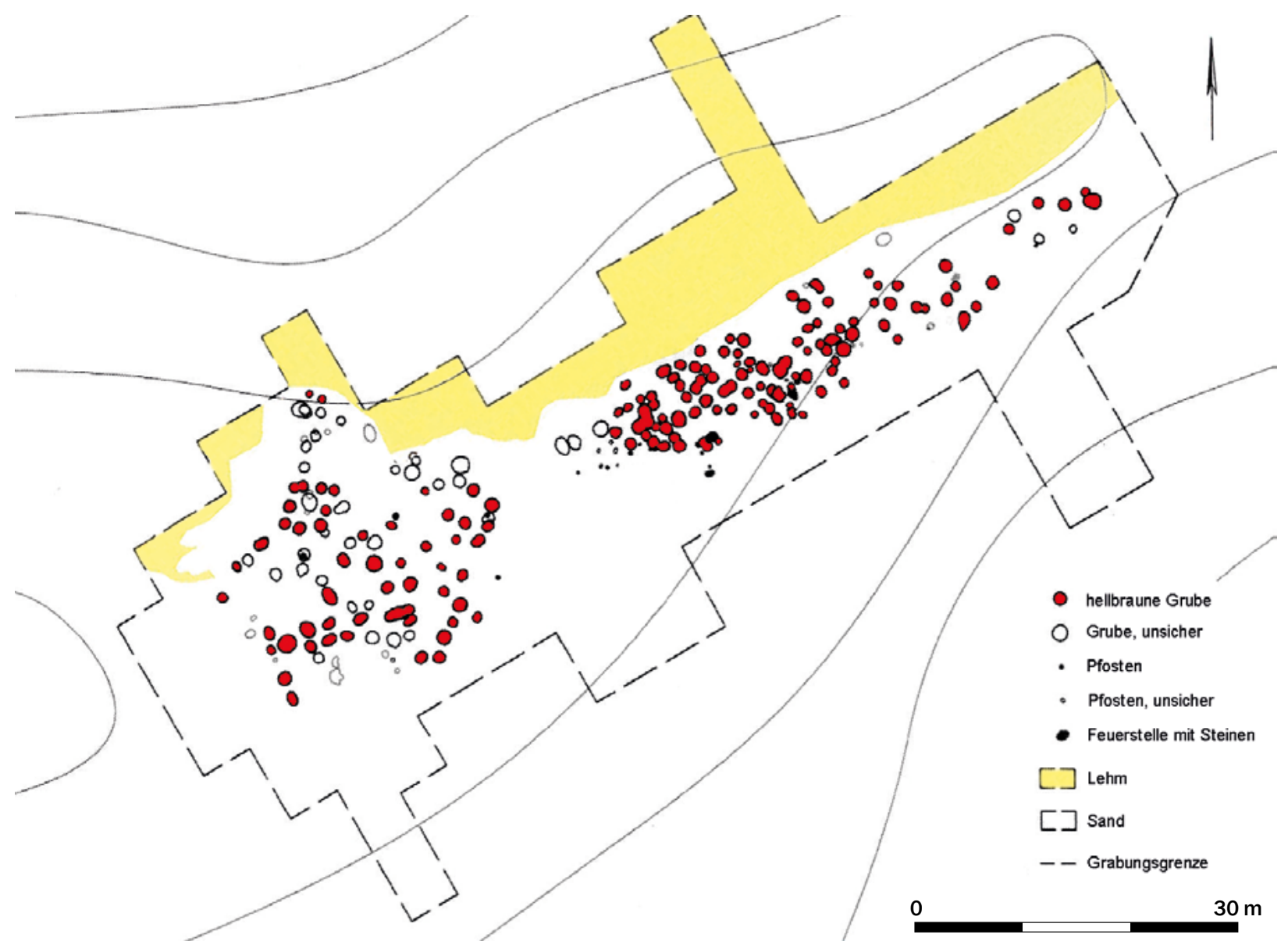

Abb. 15. Plan des Speicherareals Horno 32 (modifiziert nach BöNISCH 2004, Abb. 18). 


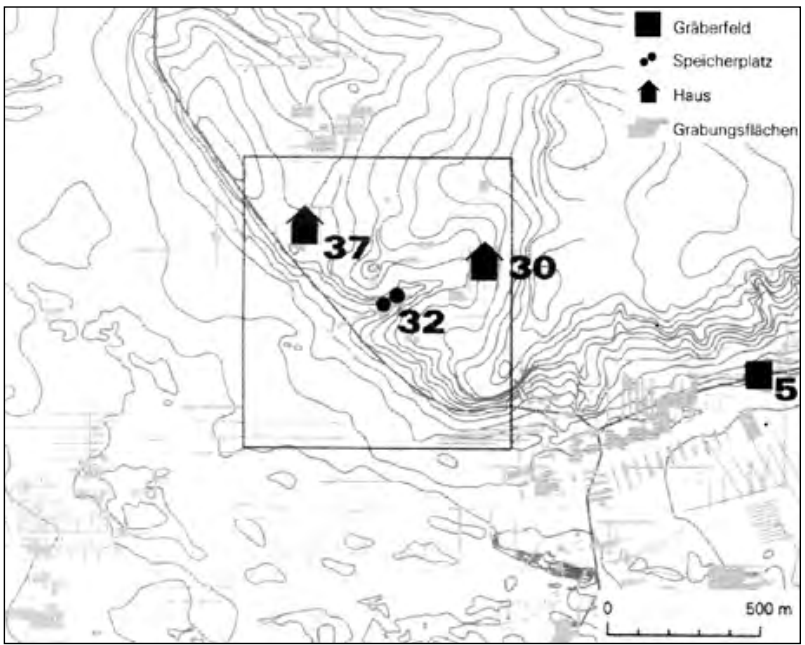

Abb. 16. Lage des Speicherareals Horno 32 in einer Talkerbe zwischen den beiden Gehöften Horno 30 und Horno 37 (modifiziert nach BöNISCH 2004, Abb. 20).

Sicherheit bestimmt werden, welche Siedlung welches Speicherareal benutzte, das enge Netz zeitnaher Fundstellen legt diese Entfernungen jedoch nahe (Abb. 17). ${ }^{89}$

Eberhard Bönisch vermutet, dass sich in den Speicherarealen die zugehörigen Siedlungen oder Gemeinschaften bestimmter Größe und Zeitspanne ähnlich wie bei Grabgruppen widerspiegeln. Neben der Fläche und Grubenzahl der Areale kann auch die Anordnung der Gruben Hinweise darauf geben. Es fallen zahlreiche Überschneidungen trotz offensichtlicher Freiflächen dazwischen auf. Häufig sind zwei brillenförmige Grubenpaare zu beobachten. Auch Reihen von drei, vier, fünf oder mehr Gruben sind erkennbar. Daraus kann entweder geschlossen werden, dass die Speichergruben sukzessiv angelegt wurden und sich aufgrund des begrenzten Platzes häufig überschneiden, oder solche Gruppierungen stellen gleichzeitig gegrabene Speicher dar. Somit könnte es sich dabei um die Speicher eines Jahres handeln. Die etwa 100 Gruben der Plätze Horno 32 Ost und West (48) sowie Pritzen 23 und $61(50,52)$ und Groß Jauer 8 (45) sind womöglich die Speicher einer Generation oder Hausphase. Bei einer Zeitspanne von 25 bis 30 Jahren wurden demnach jährlich drei bis vier Gruben angelegt, die sich in kurzen Reihen bemerkbar machen. ${ }^{90}$ Das würde auch bedeuten, dass die Gruben nur zur einmaligen Benutzung angelegt worden waren. Betrachtet man die instabilen Sandböden, in denen die Gruben errichtet wurden, ist dies durchaus vorstellbar. Zwar waren die Erdspeicher

89 BÖNISCH 1996, 89-90. - BÖNISCH 2006b, 43.

90 BöNIsCH 2004, 96. - BöNIsCH 2006a, 324-325. offenbar ausgesteift, nach einmaliger Verwendung hätten die Konstruktionen jedoch ausgewechselt werden müssen. Der Aufwand, die Grube über die Phase der Leerstehung abzuschließen, die instabilen Grubenwände zu stabilisieren und danach wieder für eine erneute Speicherung herzurichten, wurde offensichtlich nicht betrieben. Neue Gruben im einfach zu grabenden Sandboden anzulegen, bedeutete eine Arbeitsreduktion. ${ }^{91}$

Die Lausitzer Speichergruben sind mit einem durchschnittlichen Volumen von $0,8 \mathrm{~m}^{3}$ prägnant kleiner als Anlagen in anderen Regionen..$^{92}$ Diese Tatsache und die wahrscheinlich deutlich kürzere Benutzungsdauer der einzelnen Gruben andernorts führten zum Anwachsen von solch großen Speicherplätzen innerhalb kurzer Zeit.

Die häufig geradlinigen äußeren Begrenzungen der Areale vermitteln den Eindruck von festgelegten, vielleicht umfriedeten Plätzen, deren Grundform meist kreisförmig bis oval ist. Andere Gestaltungen ergeben sich durch die Anpassung ans Gelände wie die länglichen Formen in Grießen 1 (44) auf einem Sporn und Horno 32 (48) in einer Talkerbe. In Groß Lieskow 203 (46) und Horno 32 (48) scheinen die Gruben zunächst entlang der Ränder und anschließend eher ungeordnet in der Innenfläche angelegt worden zu sein. Die Ausdehnungen betragen meist zwischen 20 und $30 \mathrm{~m}$ bei einer Fläche von etwa $500-600 \mathrm{~m}^{2} .{ }^{93}$ Das größte vollständig gegrabene Speicherareal Heinersbrück 45 (47) weist Maße

91 Aussteifungen in Form von Weidegeflechten werden angenommen. Die weißen Sandsäume am Rand einiger Gruben werden als Resultat einrieselnden Sandes zwischen das Weidegeflecht gesehen. - Bei der Fundstelle Grießen 1 sind weiße Sandsäume am Grubenrand erkennbar, die durch einrieselnden Sand entstanden sind: BöNIsCH 1999, 54 sowie BöNISCH 2000, 142-143, bes. Abb. 139. - Bei den Fundstellen Pritzen 27 und Klein Jauer 9 werden Holzkohlereste von Pappel und Weide sowie ein helle Bleichsandsäume als Indizien für eine Flechtwerkauskleidung angesprochen: BöNisCH 2006a, 313. - Bei der Fundstelle Heinersbrück 45 sind bei 137 von 383 untersuchten Gruben ebenfalls hellgraue bis weiße Randsäume erkennbar: UHL 2003, 57-58. - Auf der Fundstelle Neuendorf befinden sich „zylindrische oder konisch nach oben verjüngende Gruben, die - teilweise nachweisbar - ehemals eine Wandverkleidung (aus einem Rutengeflecht) besessen haben ": Buck 1985, 88. - Bei der Fundstelle Dolgelin 5 sind Auskleidungen als dunkler Rand erkennbar: Peter-Röcher 2011, 94-95, bes. Grube 62, Abb. 14-16. - Bei der Fundstelle Klein Görigk sind ebenfalls Rückstände einer Auskleidung der Grubenwände sichtbar: UHL, BRUMLICH 2007, 44 sowie UHL, BöNISCH 2008, 138. - ReYNOLDs 1974, 127 stellte bei Experimenten fest, dass sich auf den Flechtwerken eine Mikroflora bildet. Daher müsste das Flechtwerk seiner Einschätzung nach jährlich ausgewechselt werden. 92 Die Gruben weisen meist einen Durchmesser von $1 \mathrm{~m}$ und eine Sohlentiefe von $2 \mathrm{~m}$ auf: BöNISCH 2006a, 325. - Vgl. auch BöNISCH 1996, 85 sowie BöNIsCH 2004, 96.

93 BöNIsCH 2006a, 323-324. 


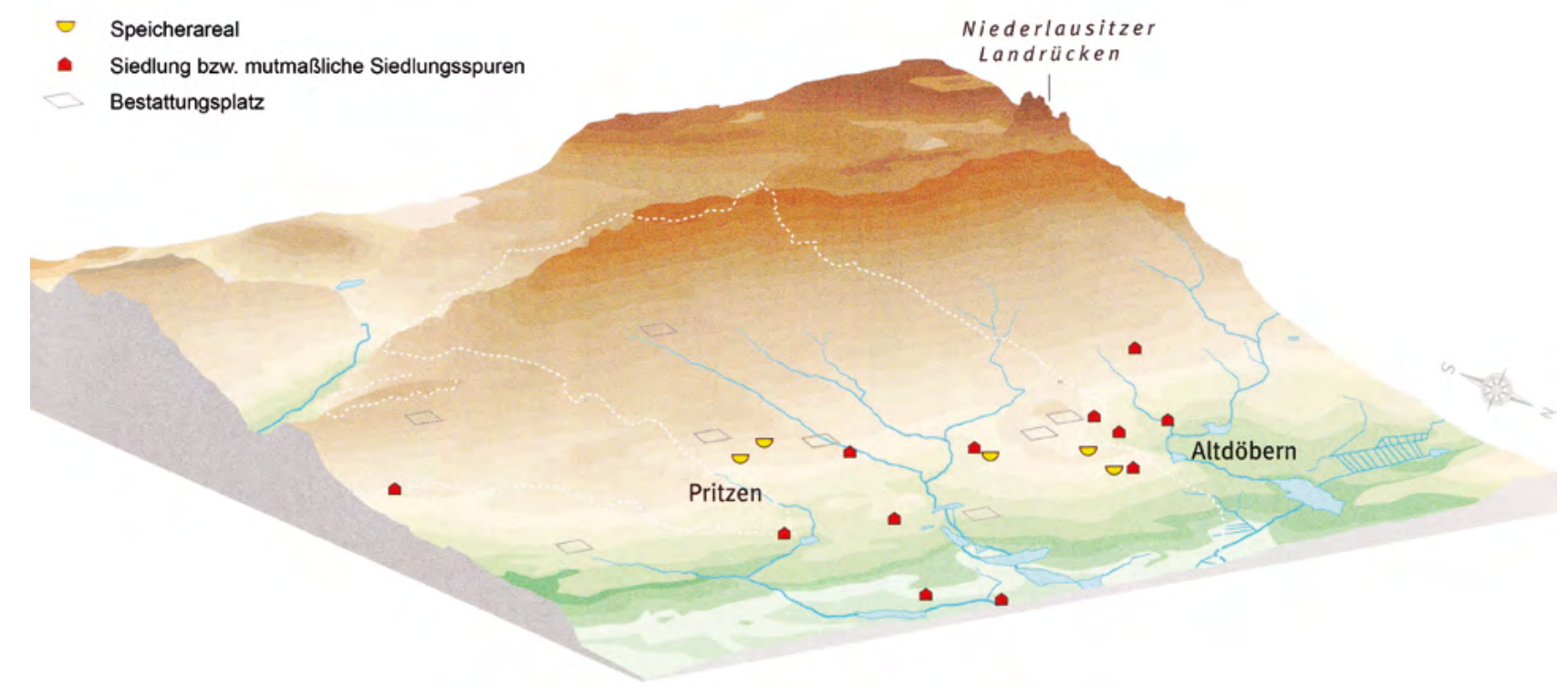

Abb. 17. Gebiet am Oberlauf der Kzschischoka mit Fundstellen der Jungbronzezeit (modifiziert nach BöNIscH 1996, Abb. 95).

von $35 \times 50$ m auf. ${ }^{94}$ Seine elliptische Form ergibt eine Fläche von etwa $1200 \mathrm{~m}^{2}$.

Wie bereits erwähnt, sind diese Speicherplätze unter anderem dadurch charakterisiert, dass kaum andere zeitgleiche Befunde wie Pfostengruben von Wohnhäusern darin vorkommen. In Horno 32 (48) kamen vor allem im westlichen Teil große eingegrabene Gefäße zwischen den Gruben zu Tage. Die Töpfe mit einem Fassungsvermögen um die 50 Liter deutet Bönisch als Transportmittel und als Utensil, um damit das Getreide in die Gruben zu schütten beziehungsweise sie zu entleeren. ${ }^{95}$ Eingegrabene Vorratsgefäße sind in situ auch aus anderen Fundplätzen bekannt, etwa der Siedlung Georgensgmünd (9), ${ }^{96}$ und können primär auch zur Speicherung kleinerer Mengen an Vorräten eingesetzt worden sein.

Ein Blick über das Untersuchungsgebiet hinaus zeigt, dass große Speicherareale in der Spätbronzezeit keine singuläre Erscheinung der Lausitz sind. In Südosteuropa, etwa in Bulgarien, sind in den letzten 30 Jahren viele Komplexe mit hunderten Gruben entdeckt worden, die keine Hausgrundrisse oder sonstige Indizien auf Siedlungen aufwiesen. Meist in den fruchtbaren Tälern der Flussläufe gelegen, führte deren Deutung zu großen Diskussionen. $\mathrm{Da}$ in vielen der Gruben zahlreiche Skelette gefunden wurden, wird von manchen der Standpunkt vertreten, es handle sich hier um

94 UHL 2003, 56.

95 BÖNISCH 2003, 114-115.

96 Honig, Specht, Nadler 2008, 36.
Kultplätze. ${ }^{97}$ Doch auch wenn einige Gruben einen sekundären rituellen Nutzen erfuhren, scheint es nicht treffend, die ganzen Anlagen kultisch zu deuten.

\section{Ein Blick auf historische Speicher-Verteilungsmuster}

Da Vorratsgruben funktionale Einrichtungen sind und die Prozesse im Inneren überall und zu jeder Zeit gleich ablaufen, sind Vergleiche mit Objekten aus anderen Zeitepochen sowie das Hinzuziehen von historischen und ethnografischen Quellen zulässig und notwendig. Dadurch wird die Quellenlage enorm vergrößert, und es werden mögliche Antworten auf Fragen zu spätbronzezeitlichen Objekten gefunden, die archäologische Hinterlassenschaften nicht erklären können. In Appendix 2 sind Zitate aus historischen Quellen aufgeführt. Diese Angaben sind natürlich nicht eins zu eins auf spätbronzezeitliche Ansiedlungen übertragbar, vermitteln aber dennoch einen Eindruck, wo es Sinn machte, Vorratsgruben anzulegen und aus welchen Gründen dies geschah. Es wird deutlich, dass neben günstigen Umweltbedingungen wie einem standfesten, trockenen Boden, der möglichst hoch über dem Grundwasser lag, auch kulturelle und soziale Aspekte eine wichtige Rolle

97 Georgieva 1991 war die erste, die die Gruben in einen kultischen Kontext stellte. Diese Überlegungen wurden von anderen aufgegriffen, wobei Standpunkte entstanden, wonach diese Plätze als Kultplätze gedeutet werden müssen. Sie erhielten die Bezeichnung "Grubenheiligtümer“. - Vgl. dazu Tonkova 2010. - Georgieva 2015. - Bozkova 2016. Die Diskussion ist noch nicht abgeschlossen, wodurch sich endgültige Urteile kaum treffen lassen. 
bei der Wahl des Platzes zum Anlegen einer Grube spielten. So richtete sich diese Entscheidung zunächst nach der Größe der Gemeinschaft: War es ein einzelner Weiler, ein Dorf oder eine größere Ansiedlung? War die Speicherung kollektiv geregelt oder konnte, beziehungsweise musste, jeder selbst darüber entscheiden? Durften überall Gruben errichtet werden oder gab es Regeln, die bestimmte Plätze dafür ausschlossen? Wie waren die Eigentumsverhältnisse der Areale in und um die Siedlung geregelt? Die Wahl des Platzes hing natürlich auch von den Erbauern selbst ab. Wollten sie das Speichergut so gut wie möglich schützen, es also entweder möglichst gut verstecken oder es ständig im Blickfeld haben? Legten sie eher Wert auf eine praktische Verortung, was sowohl das Befüllen, Entleeren als auch die Lage der Grube im täglichen Leben, etwa in einem nicht störenden Bereich, betreffen konnte?

Ebenso wie auf spätbronzezeitlichen Fundstellen ist auch aus historischen Zeiten eine große Vielfalt in der Verteilung der Gruben feststellbar (siehe Appendix 2). Speichergruben befanden sich sowohl in Siedlungen als auch außerhalb. Sie kamen verteilt in der Siedlung vor, wobei jede Wirtschaftseinheit ihre eigenen Gruben besaß, oder sie konzentrierten sich als gemeinschaftliches Speicherareal auf einem Platz. Des Weiteren wurden sie auf Äckern und neben Straßen angelegt und manche auch innerhalb von Häusern. Es wird deutlich, dass zu Kriegszeiten die besser zu versteckenden Standorte gewählt wurden. Nicht eindeutig herausgestellt wird, ob die strukturelle Verteilung der Speichergruben einer Gemeinschaft einheitlich war oder ob es auch Mischformen gab. Somit stellt sich die Frage, ob Vorratsgruben bei jeder Wirtschaftseinheit vorhanden waren, wenn es gleichzeitig ein gemeinschaftliches Speicherareal gab.

Zur Anzahl der Vorratsgruben je Wirtschaftseinheit schreibt der tschechische Ethnologe Ludvík Kunz, dass mehrere Speicher für unterschiedliches Getreide dienten. Deshalb besaß ein Hof mindestens zwei bis drei Gruben. Die Anzahl entsprach den maximalen Ernteerträgen, das heißt, nicht alle Speichergruben wurden jedes Jahr gefüllt. Eine größere Anzahl an Gruben bedeutete auch Sicherheit, da bei Überfällen die Chance höher war, dass nicht alle Speicher gefunden wurden. Ebenso verminderte man so das Risiko, viel Getreide zu verlieren, falls eine der Gruben versagte. Die Zahl der Gruben zeigt deshalb weder die exakte Getreideproduktion noch die Größe der bewirtschafteten Fläche oder das Verhältnis angebauter Arten an. ${ }^{98}$

\section{Schlussfolgerung}

Es ist festzustellen, dass man in der Spätbronzezeit sowohl individuelle als auch kollektive Vorratshaltung betrieb, wobei erstere wohl überwog. Entsprechend dem Forschungsstand ist erkennbar, dass die Lagerung von Lebensmitteln in der Spätbronzezeit überwiegend individuell auf Basis kleiner Gruppen oder je nach Wirtschaftseinheit erfolgte. In ländlichen Siedlungen und Gehöften, aber auch in großen Ortschaften und manchen Zentren wird ersichtlich, dass dort Speichergruben mit Bezug zu einzelnen Häusern angelegt wurden. Dies lässt den Schluss zu, dass die Lagerung dort von jeder Wirtschaftseinheit selbst und auf vermutlich eigenem Grundstück durchgeführt wurde. Auch innerhalb der Häuser wurden Nahrungsmittel kurzfristig und wohl auch langfristig in Gruben gelagert. Nicht immer kann besagtes zweifelsfrei festgestellt werden, da in den meisten Fällen keine Hausgrundrisse nachzuweisen sind. Deutlich erkennbar ist diese Art der Bevorratung bei Siedlungen mit Hofplatzkonstanz. Wurden häufiger Hofplätze verlegt, ergibt sich ein Bild eines auf den ersten Blick undurchschaubaren Durcheinanders an Gruben. Mit einer feinen chronologischen Gliederung und statistischen Methoden können solche Plätze entschlüsselt werden. Individuelle Vorratshaltung konnte auch außerhalb der Siedlung auf den zugehörigen Äckern stattfinden, ist allerdings schwerer archäologisch nachzuweisen und bis dato wohl unterrepräsentiert. Ortschaften, in denen jede Wirtschaftseinheit selbst für die Lagerung ihrer Lebensmittel zuständig war, sind im ganzen Untersuchungsgebiet feststellbar. Es handelt sich meist um kleinere Siedlungen oder einzelne Gehöfte, die stark landwirtschaftlich geprägt gewesen sein dürften.

Das Auftreten kollektiver Speicher resultiert aus dem gesellschaftlichen Wandel jener Zeit, in der die sozioökonomischen Verhältnisse grundlegenden Änderungen unterworfen waren. War zuvor meist jeder selbst für die Lagerung der Lebensmittel verantwortlich, entstanden nun auch große Speicherareale, die von der Gemeinschaft genutzt, bewacht und im Notfall gegen Feinde verteidigt werden konnten. Vor allem in Zentralsiedlungen und größeren Siedlungen beziehungsweise in Siedlungssystemen, die sich durch eine geplante Bebauungsstruktur auszeichnen, nutzte man einen oder mehrere Sektoren ausschließlich für gemeinschaftliche Vorratshaltung. Dieser Platz lag in manchen Fällen im Zentrum auf einem unbebauten Platz, in anderen randlich oder einige Meter von den Häusern entfernt. Eine Sonderform bildete sich in den Sandböden der Niederlausitz heraus. Hier entstanden einige hundert Meter von den Wohnplätzen entfernt große Speicherareale. Derartige Plätze wurden erst im Zuge der großflächigen Ausgrabungen, bedingt durch den Braunkohleabbau, entdeckt. Vorstellbar ist demnach, dass andernorts ebenso gemeinschaftlich außerhalb der Siedlungen gespeichert 
wurde, diese Orte allerdings bislang noch nicht gefunden worden sind. Historische Quellen zeigen, dass dies keine singuläre Erscheinung einer spätbronzezeitlichen Gemeinschaft war, sondern auch in anderen Zeiten so praktiziert wurde (siehe Appendix 2).

Mit Blick auf die Verteilung der Siedlungen mit kollektiver Vorratshaltung wird klar, dass die Verortung der Speicherareale im Untersuchungsraum nicht unmittelbar kulturelle Gründe hatte. Im gleichen Gebiet wurden die Areale in einem unterschiedlichen Bezug zu den Wohnstätten angelegt. Offenbar war für manche Siedlungen eher ausschlaggebend, dass die Untergrundbedingungen für die Speichergruben bestmöglich waren, während andere darauf achteten, die Speicherareale strukturell in das Siedlungsbild einzupassen, nämlich dort, wo sie optimal zu beobachten beziehungsweise zu verteidigen waren. Große und daher eindeutig kollektive Speicherareale kommen hauptsächlich nördlich der Mittelgebirgszone vor. Auch hier sind die Ursachen, wie in Abbildung 1 ersichtlich ist, wohl nicht in unterschiedlichen kulturellen Ausprägungen zu suchen, sondern in der Stabilität des Untergrundes. In den betroffenen Gebieten ist instabiler, sandiger Boden vorherrschend. Große, dicht belegte Speicherareale zeugen daher auch von der Kurzlebigkeit der Gruben und den daraus folgenden, wohl jährlichen Neuanlegungen. Erdspeicher südlich der Mittelgebirgszone, die dort vor allem in stabilen Untergrund gebaut wurden, konnten dagegen über mehrere Jahre und bei guter Pflege auch über mehrere Generationen hinweg benutzt werden. Aus diesem Grund bildeten sich dort keine dicht belegten Speicherareale, die als Platz für eine gemeinschaftliche Vorratshaltung sofort ins Auge stechen.

Obwohl zweifelsfreie Speicherareale südlich des Mittelgebirges bislang nicht ausgemacht werden konnten, sind vor allem in östlichen Gebieten wenige Plätze mit möglicher kollektiver Lagerung anzusprechen. ${ }^{99}$ Diese weisen zwar keine derart extreme Grubendichte auf wie nördlichere Exemplare, die Speicher befanden sich aber in einem bestimmten Bereich der Siedlung.

Anzumerken ist, dass sich gemeinschaftliche Lagerung von Lebensmitteln nicht nur durch die Anordnung von Speichergruben bemerkbar machen kann. Auch die Größe der Gruben kann als Indiz dafür genommen werden, ob hier nur eine Wirtschaftseinheit die Ernte lagerte oder ob mehrere Bauern die Speicher befüllten. Dabei stehen den kleinsten Speichergruben von 0,5-1 $\mathrm{m}^{3}$ die größten Objekte mit deutlich über $10 \mathrm{~m}^{3}$ gegenüber. ${ }^{100}$

Andere Lagermöglichkeiten wie halbeingetiefte, ebenerdige oder oberirdisch auf Stelzen errichtete Anlagen sind in den meisten Fällen aufgrund von Bodenerosion nicht mehr nachweisbar. Auch diese können gemeinsam errichtet, befüllt und bewacht worden sein. Vermutlich spielten im südlichen Mitteleuropa auch Großgefäße für die Lagerung von Lebensmitteln eine größere Rolle als im Norden. Die Ursache dafür liegt in der starken Beeinflussung durch den Südosten Europas, in dem die Vorratshaltung in Pithoi dominierend war und zu jener Zeit bereits eine lange Tradition besessen hatte. ${ }^{101}$

Sticht im südlichen Mitteleuropa kollektive Vorratshaltung nicht sofort hervor, liegt das vor allem an der Langlebigkeit der Gruben in meist stabilem Untergrund und dem Fehlen der kompletten Übersicht aller Speicheranlagen, also auch oberirdischer. Betrachtet man lediglich die unterirdischen Speicher, kann in eindeutigen Fällen kollektive beziehungsweise individuelle Vorratshaltung angenommen werden. Ausgeschlossen werden kann dagegen in den übrigen Fällen keine der beiden Methoden. Ob gemeinschaftliche Speicherareale lediglich von einer einzigen Siedlung oder Zentralorten wie Stillfried (38) und Brno Obřany (26) betrieben wurden oder von mehreren, und ob Bauern aus dem Umland Teile ihrer Ernte an Zentren etwa im Gegenzug für Schutz abgeben mussten, muss bislang offen bleiben. Unklar bleibt in diesem Zusammenhang, woher die Menge der gelagerten Nahrungsmittel in Zentralorten kommt, das heißt, ob diese nur durch die Bewohner beziehungsweise Nutzer dieser Zentren erwirtschaftet wurden.

\section{Danksagung}

Diese Arbeit wurde im Rahmen des FWF-Projekts P28005-G25 „Ressourcensicherung, Macht und Kult in Stillfried?“ verfasst. Mein Dank gilt Prof. Dr. Barbara Horejs, die mich zum hier behandelten Thema im Rahmen meiner Masterarbeit betreute. Ebenfalls danken möchte ich den Projektleiterinnen des Stillfried-Projekts Dr. Michaela Lochner und Dr. Monika Griebl sowie dem Leiter der Forschungsgruppe „Urnfield Culture Networks“ Dr. Mario Gavranović für die erkenntnisreichen Diskussionen. Für Informationen zur Situation der Hünenburg bei Watenstedt danke ich Dr. Immo Heske. Die Beratung der Situation in Bulgarien übernahm Dr. Hristo Popov. Des Weiteren gebührt Dank Prof. Dr. Marianne Kohler-Schneider, Dr. Michaela Popovtschak sowie Dr. Ulf Baum für die fachliche Beratung bei botanischen und agrartechnischen Fragen.
99 Vgl. Horní Moštěnice: JAšKová 1968. - KüHnholz 2013, 18. Hulín: SPURnÝ 1953. - TrŇAČKovÁ 1958. - SPURnÝ 1971. - KÜHNHolz 2013, 17-18. - Mohelnice: TichÝ 1971. - Kühnholz 2013, 18. - Palonín: Goš, Kapl, Nekvasil 1980. - Goš, Kapl, Nekvasil 1981. - KüHnholz 2013, 18.
100 Einige der Speichergruben von Stillfried weisen derart große Volumina auf, z. B. die Objekte V2713 und V704.

101 Z. B. Zabrana 2009, bes. 391-392. 
Appendix 1.

Fundstellentabelle, zunächst geordnet nach Speicherstrategie, anschließend alphabetisch nach Land, Region sowie Fundstelle.

\begin{tabular}{|c|c|c|c|}
\hline Nr. & Fundstelle & Land & Literatur \\
\hline \multicolumn{4}{|c|}{ Individuelle Speicherung innerhalb der Siedlung } \\
\hline 1 & Březno & CZ, Ústecký kraj & $\begin{array}{l}\text { Pleinerová, Hrala 1988. - JiráŇ et al. 2008, bes. 168-170. - Parma } \\
\text { 2015, bes. 100-101. }\end{array}$ \\
\hline 2 & Brno-Medlanky & CZ, Jihomoravský kraj & PARMA, mündl. \\
\hline 3 & Ivanovice na Hané & CZ, Jihomoravský kraj & Parma 2004. - Parma 2011, 172-182. \\
\hline 4 & Roztoky & CZ, Středočeský kraj & KunA et al. 2012. \\
\hline 5 & Vikletice & CZ, Ústecký kraj & Bouzek, KouteckÝ, NeustupnÝ 1966, bes. 78-82. \\
\hline 6 & Burkheim-Burgberg & DE, Baden-Württemberg & Dehn 1985. - Dehn 1989. - Grimmer-Dehn ca. 1990. \\
\hline 7 & Burgweinting & DE, Bayern & Dallmeier, Froschauer 1997. - Zuber 2010. - Zuber 2013. \\
\hline 8 & Erlingen & DE, Bayern & Hainski, Mattheusser, BütTNer 2005. \\
\hline 9 & Georgensgmünd & DE, Bayern & Honig, Specht, Nadler 2008. \\
\hline 10 & Berlin-Buch & DE, Berlin & Kiekebusch 1923. - Wanzek 2004. - Beran, Suhr 2012. \\
\hline 11 & Berlin-Lichterfelde & DE, Berlin & VON MÜLLER 1964. \\
\hline 12 & Mahlow 14 & DE, Brandenburg & STAPELFELDT 2014. \\
\hline 13 & Pritzen 63 & DE, Brandenburg & BEHNKE 2003. - SCHWARZLÄNDER 2003. - BÖNISCH 2006a. \\
\hline 14 & Hamburg-Boberg & DE, Hamburg & SCHINDLER 1958. - SCHNEIDER 1974. - Busch 1975, 54-55. \\
\hline 15 & Bleckede-Alt Wendischthun & DE, Niedersachsen & AsSENDORP 2013, bes. 133-134. \\
\hline 16 & Hitzacker & DE, Niedersachsen & $\begin{array}{l}\text { AsSENDORP 1991. - NiKULKA 1991. - AssENDORP 1997. - AsSENDORP } \\
\text { 2013, bes. 112-114. }\end{array}$ \\
\hline 17 & Hünenburg & DE, Niedersachsen & $\begin{array}{l}\text { Steinmetz 1999. - Heske 2003. - Posselt 2003. - Willroth 2003. - } \\
\text { Heske 2006. - Heske 2010. - Heske et al. 2010. - Heske } 2016 .\end{array}$ \\
\hline 18 & Ochtmissen & DE, Niedersachsen & GEBERs 1997. - Assendorp 2013, bes. 114-115. \\
\hline 19 & Eschweiler-Lohn & DE, Nordrhein-Westfalen & Schwellnus, Hermanns, Brown 1983. \\
\hline 20 & Rees & DE, Nordrhein-Westfalen & van DE GRAaF, SARna 2004. \\
\hline 21 & Ochtendung & DE, Rheinlandpfalz & Tischler 1951. \\
\hline 22 & Brehna & DE, Sachsen-Anhalt & vON RauchHaupt, Schunke 2010. \\
\hline 23 & Wallwitz & DE, Sachsen-Anhalt & STAHLHOFEN 1985. \\
\hline 24 & Érd & HU, Közép-Magyarország & Oravecz, Mráv 2009. \\
\hline 25 & Dolný Kubín-Medzihradné & SK, Žilinský kraj & ČAPLOVIČ 1975. - ČAPLOVIČ 1978. \\
\hline \multicolumn{4}{|c|}{ Gemeinschaftliches Speicherareal innerhalb der Siedlung } \\
\hline 26 & Brno Obřany & CZ, Jihomoravský kraj & ADÁMEK 1961. \\
\hline 27 & Frankfurt (Oder) & DE, Brandenburg & Hummel, Soeters 1999. - Uschmann 2000. \\
\hline
\end{tabular}


Appendix 1. Fortsetzung.

\begin{tabular}{|c|c|c|c|}
\hline Nr. & Fundstelle & Land & Literatur \\
\hline 28 & Rathsdorf 5 & DE, Brandenburg & 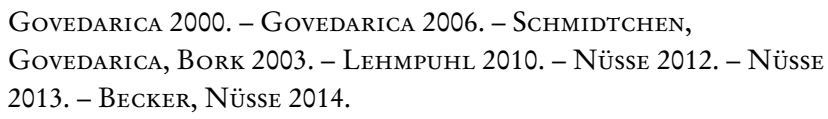 \\
\hline 29 & Waltersdorf 10 & DE, Brandenburg & STARK 2006. \\
\hline 30 & Waltersdorf 11 & DE, Brandenburg & STARK 2006. \\
\hline 31 & Zeuthen & DE, Brandenburg & SChLEGEL, Wiegert 2006. \\
\hline 32 & Hittfeld & DE, Niedersachsen & SiELmanN 1974. \\
\hline 33 & Rullstorf & DE, Niedersachsen & $\begin{array}{l}\text { Gebers 1985. - Kirleis 2002. - Kirleis 2003. - Gebers 2004. - } \\
\text { Kirleis 2004. - Gebers } 2009 .\end{array}$ \\
\hline 34 & Esperstedt & DE, Sachsen-Anhalt & Glaser, Döhle 2006. \\
\hline 35 & Haldensleben-Südhafen & DE, Sachsen-Anhalt & WAGNER et al. 2012, bes. 70-79. - WAGNER 2014. \\
\hline 36 & Haldensleben-Beberdüker & DE, Sachsen-Anhalt & KNOLL 2012. - WAGNER et al. 2012, bes. 79-85. \\
\hline 37 & Zieko & DE, Sachsen-Anhalt & GanSLMEIER 2004. \\
\hline 38 & Stillfried & AT, Niederösterreich & Hellerschmid 2006. - Griebl et al. 2017. \\
\hline 39 & Brześć Kujawski & $\begin{array}{l}\text { PL, Województwo kujaws- } \\
\text { ko-pomorskie }\end{array}$ & KASZEWSKi 1967. - MichalsKi 1986, 79-80. \\
\hline 40 & Turbia & $\begin{array}{l}\text { PL, Województwo podkar- } \\
\text { packie }\end{array}$ & Zeylandowa 1963. - Michalski 1986, 78-79. \\
\hline \multicolumn{4}{|c|}{ Individuelle Speicherung außerhalb der Siedlung } \\
\hline 41 & Sinzing & DE, Bayern & Petrosino, Putz 2003. \\
\hline 42 & Hafnerbach & AT, Niederösterreich & GöLLER 1996. \\
\hline 43 & Wien-Unterlaa & AT, Wien & SAmonig 2002. - PenZ 2011. \\
\hline \multicolumn{4}{|c|}{ Gemeinschaftliches Speicherareal außerhalb der Siedlung } \\
\hline 44 & Grießen 1 & DE, Brandenburg & BÖNISCH 1999. - BÖNISCH 2000, 142-143. - BÖNISCH 2006a. \\
\hline 45 & Groß Jauer 8 & DE, Brandenburg & BÖNISCH 1996, 226-234. - BÖNISCH 2006a. \\
\hline 46 & Groß Lieskow 203 & DE, Brandenburg & PASDA 1997. - PASDA 2002. - BÖNISCH 2006a. \\
\hline 47 & Heinersbrück 45 & DE, Brandenburg & UHL 2003. \\
\hline 48 & Horno 32 & DE, Brandenburg & BÖNISCH 2003. - BÖNISCH 2004, 116-118. - BÖNISCH 2006a. \\
\hline 49 & Merzdorf 33 & DE, Brandenburg & HiRSEKORN 2003. - BÖNISCH 2006a. \\
\hline 50 & Pritzen 23 & DE, Brandenburg & BÖNISCH 1996, 343-351. - BÖNISCH 2006a. \\
\hline 51 & Pritzen 27 & DE, Brandenburg & BÖNISCH 1996, 352-358. - BÖNISCH 2006a. \\
\hline 52 & Pritzen 61 & DE, Brandenburg & BÖNISCH 1998. - BÖNISCH, WIERMANN 1998. - BÖNISCH 2006a. \\
\hline
\end{tabular}




\section{Appendix 2.}

\section{Historische Nennungen zur Verteilung von Speichergruben}

Johan Arnholds von Brand 1673 (publiziert 1702) über Bauern in „Lieffland“ (heutiges Estland und Lettland):

„Auch haben sie meistentheils unter ihnen diesen gebrauch, daß sie, zu zeit anstehenden Kriegs, oder auch wohl in friedens zeiten, [...] ihr meistes Korn [...] in eine tieffe, auf ihrem acker, oder beygelegenem berge, außgegrabene höhle hinein werffen $[\ldots]^{\text {“102 }}$

Wolf Helmhardt von Hohberg 1695 über Bauern in Ungarn:

„Sie machen aber dergleichen Gruben unferne von ihren Häusern, daß sie leicht darauf sehen können“. ${ }^{103}$

Anonymus 1772 über Bauern in Ungarn:

„Die Getreidegruben werden entweder vor einem jeden Hause, oder auf einem gemeinen Platz gegraben. Zuweilen geschiet es auch auf den Güthern im Felde, und neben den Aeckern, wo das Getreide ausgetreten wird. Diese sind öfters 1, 2, bis 3 ungarische Meilen von der Stadt entfernt. Hierzu wird nun ein Platz ausgesucht, der etwas erhaben, und einen letticht oder thonichten Grund hat. “104

Franz Benedikt Hermann 1782 über Bauern in Ungarn:

„Diese Gruben werden entweder vor den Häusern, den Aeckern, oder auf Gemeinplätzen gemacht, $[\ldots]^{\text {“105 }}$

\section{Johann Georg Krünitz 1788:}

„Diese Höhlen oder Gruben in der Erde sind entweder einzeln, oder es sind ihrer mehrere beysammen; [...] Sie werden bisweilen nahe an den Häusern, bisweilen auch auf freyem Felde bey den Aeckern, angelegt. “106

„Diejenigen, welche keine solche leere Höhlen zur Sicherheit ihrer Schätze fanden, [...] sahen sich genöthigt, neue zu graben; und man that dieses entweder in der Nähe seines Hauses, oder auf seinen Feldern. Nachdem der Krieg einige Jahre gedauert $[\ldots]$ hatte, $[\ldots]$ nutzte man diese eigenthümliche Höhlen auch in Friedens-Zeiten, und so wurden sie die ordentlichen Magazine und Vorraths-Kammern. “107

„Da sich indessen eine solche Grube, wenn sie gleich mit Rasen dem anliegenden Boden gleich gemacht ist, arglistigen Personen von selbst verräth, indem, wenn im Sommer früh

102 VON BRAND 1702, 144.

103 von Hohberg 1695, 73.

104 AnONymus 1772, 213.

105 Hermann 1782, 253

106 KRÜNITZ 1788, 649.

107 KRÜNITZ 1788, 651. der Thau aller Orten auf dem Erdreiche verspürt wird, der Platz, so weit eine solche Grube geht, trocken ist: so wäre es am besten und sichersten, wenn man unter seinem Hause, oder von dem Keller aus, die Grube verfertigte, so würde sie auch vor den Nachbarn verborgen bleiben, und noch dazu dienen, daß man bey einem schnellen Ueberfall noch das beste dahin retten könnte. “108

Joseph Anton Schlier 1825, Anweisung über das Anlegen von Speichergruben:

„Vor allem muß man aber zu dergleichen unterirdischen Magazinen die schicklichsten Plätze aussuchen lassen, so $\mathrm{daß}$ das Magazingetraid so leicht als möglich zu- und abgefahren, hinein- und herausgeschafft [...] werden kann.“109

Johann Michael Voit 1825, Anweisung über das Anlegen von Speichergruben:

„Der Oekonom, welcher Erdgruben anlegt, wird sie nicht weit von seiner Wohnung entfernt wünschen, und am liebsten wird ihm ein eingelanderter Ort, allenfalls in einem Baumgarten dazu seyn." ${ }^{110}$

Johann von Csaplovics 1829 über Bauern in Ungarn:

„Die Gruben werden [...] in die Erde im Hofe, noch mehr meist auf der Gasse vor den Häusern [...] gegraben, $[\ldots]^{\text {“111 }}$

Johann Gottfried Eisner 1834 über Bauern in Ungarn:

„Die Gruben machen die ungarischen Landleute überall in der Nähe ihrer Wohnungen, und nicht sowohl aus Mangel an Platz, sondern vielmehr, um vor Verlust durch Feuergefahr geschützt zu seyn. “112

Johann Karl Nestler 1840 über Bauern in Ungarn:

„Die Gruben werden an manchen Orten, wo es angeht, in der Scheuer vor den Wohnungen, oder in den Kammern und Wohnungen manchmal grade unter dem gemeinschaftlichen Speisetische der Familie angelegt, also an Orten, die entweder an und für sich nie ohne Aufsicht sind, oder ohnehin von den Nachtwächtern und Dorfhunden bewacht oder nach außerdem geschlossen gehalten werden und auch in Kriegszeiten gegen die ersten muthwilligen Anfälle einer flüchtigen und dem Dienste untreu gewordenen Soldateska gesichert sind. “ ${ }^{113}$

108 KRÜNITZ 1788, 661

109 SCHLiER 1825, 87.

110 VoIt 1825, 330 (Fußnote).

111 von CSAPLOVICS 1829, 12.

112 EISNER 1834, 1063.

113 Nestler 1849, 161. 
Hans G. Walter 1962 über neuzeitliche Bauern im Burgenland:

„Dieselben [Speichergruben] befanden sich jeweils in der entweder überdachten oder offenen Hauseinfahrt. [...] die Lage an einer sehr frequentierten Einfallpforte [...] mag für den Bau solcher Gruben in der Gegend um Bruck mitbestimmend gewesen sein. ${ }^{1114}$

\section{Gustaf Dalman 1933 über Bauern in Palästina:}

„Solche Gruben können im Hof des Bauernhauses, im Dorf, aber auch im Feld angelegt werden. “115

Leopold Schmid 1961 aus einer Umfrage 1955 im Burgenland:

„Die Gruben befanden sich unter der Stube oder vor dem Haus.“

„In jedem Haus waren einige „Troadgrui.“

„Sie [Speichergruben][...] befanden sich zum größeren Teil auf der Gasse, manchmal auch im Zimmer; dann war der massive Tisch über die Öffnung gestellt.“

„Man fand sie meist vor der Hausfront, aber auch mitten in der Stube und im Hof.“

„Vor der Anlage dieses Feldes (um 1860) war dieser Fleck mit größeren und kleineren Gruben übersäet und führte die Bezeichnung „Rupa“ = Grube.“

„Sie [Speichergruben] waren [...] unter dem Bretterfußboden der Wohnstube, und zwar stets an der Stelle, die der schwere Tisch einnimmt, angebracht.“

„Eine Reihe von Fruchtspeichern am Westrand des Weges von der Bahnstation in die Ortschaft. Sie stehen noch in Verwendung. “116

\section{Literatur}

ADÁMEK 1961

F. AdÁmek, Pravěké hradisko u Obran. Monografické Práce Moravského Muzea v Brně, Brno 1961.

Anonymus 1772

Anonymus, Allergnädigst privilegierte Anzeigen aus sämtlich-kaiserlich-königlichen Erbländern. Wien 1772.

AsSENDORP 1991

J. J. Assendorp, Hausgrundrisse mit Wandgräbchen aus Hitzacker. In: H. JÜrRIEs (Hrsg.), Beiträge zur Archäologie und Geschichte Nordostniedersachsens. Lüchow 1991, 95-108.

AsSENDORP 1997

J. J. Assendorp, Die bronzezeitliche Siedlung in Hitzacker, Niedersachsen. In: J. J. Assendorp (Hrsg.), Forschungen zur bronzezeitlichen Besiedlung in Nord- und Mitteleuropa. Internationales Symposium vom 9.-11. Mai 1996 in Hitzacker. Espelkamp 1997, 51-59.

114 Walter 1962, 47.

115 Dalman 1933, 195.

116 Sснмidt 1961.
ASSENDORP 2013

J. J. Assendorp, Grubenwolken: Ein jungbronzezeitliches Siedlungsphänomen im Elbegebiet. In: I. Heske, H.-J. NüsSE, J.Schneeweiss (Hrsg.), „Landschaft, Besiedlung und Siedlung": Archäologische Studien im nordeuropäischen Kontext. Festschrift für Karl-Heinz Willroth zu seinem 65. Geburtstag. Göttinger Schriften zur Vor- und Frühgeschichte 33, Göttingen 2013, 109-118.

Balassa, Ortutay 1982

I. Balassa, G. Ortutay, Ungarische Volkskunde. Budapest München 1982.

BALBo et al. 2015

A. L. Balbo, D. Cabanes, J. J. Garcia-Granero, A. Bonet, P. AjITHPRAsAd, X. Terradas, A microarchaeological approach for the study of pits, Environmental Archaeology 20/4, 2015, 390-405.

BARTL 2004

K. BARTL, Vorratshaltung: Die spätepipaläolithische und frühneolithische Entwicklung im westlichen Vorderasien: Voraussetzungen, typologische Varianz und sozio-ökonomische Implikationen im Zeitraum zwischen 12,000 und 7,600 BP. Studies in Early Near Eastern Production, Subsistence and Environment 10/2003, Berlin 2004.

BECKER, NÜSSE 2014

C. BeCKer, H.-J. Nüsse, Siedeln und Angeln mit Burgblick, Ausgrabungen in der Vorburgsiedlung von Rathsdorf, Archäologie in Berlin und Brandenburg 2012, 2014, 54-57.

BEHNKE 2003

H. J. BeHnke, Gruben, Pfosten, Wandgräbchen und Lehmbewurf eines bronzezeitlichen Hauses auf der Restlochböschung bei Pritzen. Ausgrabungen im Niederlausitzer Braunkohlenrevier 2001, Arbeitsberichte zur Bodendenkmalpflege in Brandenburg $11,2003,83-94$.

BERAN, SUHR 2012

J. Beran, B. Suhr, Neues aus dem Bronzezeit-Eldorado: Prospektionen und Rettungsgrabungen auf zwei Siedlungsplätzen bei Berlin-Buch, Archäologie in Berlin und Brandenburg 2010, 2012, 57-61.

Boенme 2001

J. Bовнме, Nur kurzzeitig genutzt: Eine Siedlung der frühesten vorrömischen Eisenzeit bei Kleinmachnow, Landkreis PotsdamMittelmark, Archäologie in Berlin und Brandenburg 2000, 2001, 68-70.

BoELICKe 1982

U. Boelicke, Gruben und Häuser: Untersuchungen zur Struktur bandkeramischer Hofplätze. In: J. PAvúk (Hrsg.), Siedlungen der Kultur mit Linearkeramik in Europa. Internationales Kolloquium Nové Vozokany 17.-20. November 1981. Nitra 1982, 17-28.

BOELICKE 1988

U. Boelicke, Die Gruben. In: U. Boelicke, D. V. Brandt, J. Lüning, P. Stehli, A. Zimmermann (Hrsg.), Der bandkeramische Siedlungsplatz Langweiler 8: Gemeinde Aldenhofen, Kreis Düren. Rheinische Ausgrabungen 28, Köln 1988, 300-394.

BÖNISCH 1989

E. BÖNISCH, Methodisches zur Erforschung der urgeschichtlichen Besiedlung in Braunkohlegebieten am Beispiel des Tagebaues Greifenhain, Braunkohle und Archäologie im Bezirk Cottbus, Sonderheft 1989, 38-45. 
BöNISCH 1996

E. BÖNIsCH, Die urgeschichtliche Besiedlung am Niederlausitzer Landrücken: Untersuchungen am Oberlauf der Kzschischoka, Forschungen zur Archäologie im Land Brandenburg 4, Potsdam 1996.

BÖNISCH 1998

E. BöNIsCH, Ein Dorfteich aus der Bronzezeit: Ausgrabungen aus Pritzen, Ot. von Lubochow, Lkr. Oberspreewald-Lausitz, Archäologie in Berlin und Brandenburg 1997, 1998, 44-47.

BöNISCH 1999

E. BöNISCH, Kleiner bronzezeitlicher Bestattungsplatz an der Neiße bei Grießen: Ausgrabungen auf der Trasse der Dichtwand des Tagebaus Jänschwalde. Ausgrabungen im Niederlausitzer Braunkohlenrevier 1998, Arbeitsberichte zur Bodendenkmalpflege in Brandenburg 3, 1999, 53-60.

BÖNISCH 2000

E. BöNIsCH, Grießen 1. Ausgrabungen im Niederlausitzer Braunkohlenrevier 1999, Arbeitsberichte zur Bodendenkmalpflege in Brandenburg 4, 2000, 142-143.

BöNISCH 2003

E. BöNISCH, Die Entdeckung bronzezeitlicher Häuser auf der Hornoer Hochfläche. Ausgrabungen im Niederlausitzer Braunkohlenrevier 2001, Arbeitsberichte zur Bodendenkmalpflege in Brandenburg 11, 2003, 101-116.

BÖNISCH 2004

E. BöNISCH, Häuser, Speicherplätze und Siedlungsmuster: Neues zu Siedlungen der Lausitzer Kultur links der Neiße. II Polsko-Niemieckie Spotkania Archeologiczne Odra - przeszkoda czy pomost w ekspansji kulturowej?, Dychów 29 kwietnia-1 maja 2004 roku. Biblioteka Archeologii Środkowego Nadodrza 2, Zielona Góra 2004, 91-120.

BöNIsch 2006a

E. BÖNISCH, Bronzezeitliche Speicherplätze in der Niederlausitz. In: W.-R. Teegen, R. Cordie, O. Dörrer, S. Rieckhoff, H. SteuER (Hrsg.), Studien zur Lebenswelt der Eisenzeit. Festschrift für Rosemarie Müller, RGA-Ergänzungsband 53, Berlin 2006, 305-332.

BÖNISCH 2006b

E. BöNISCH, Im Überblick: Ausgrabungen zur Bronzezeit 2005, Archäologie in Berlin und Brandenburg 2005, 2006, 41-44.

BöNISCH, WiERMANN 1998

E. Bönisch, R. WiermanN, Groß Jauer 39; Pritzen 61, Ausgrabungen im Niederlausitzer Braunkohlenrevier 1997, Arbeitsberichte zur Bodendenkmalpflege in Brandenburg 2, 1998, 92.

BouzeK, KouteckÝ 1964

J. Bouzek, D. KouteckÝ, Knovízské zásobní jámy, Archeologické rozhledy 16, 1964, 28-43.

Bouzek, KouteckÝ, NeustupnÝ 1966

J. Bouzek, D. KouteckÝ, E. Neustupný, The Knovíz Settlement of North-West Bohemia/Knovízské osídlení severozápadních Čech. Fontes Archaeologici Pragenses 10, Prag 1966.

BozKova 2016

A. Bozkova, Pits of the first millennium B.C. in Thrace, sine ira et studio. In: K. Bacvarov, R. Gleser (Hrsg.), Southeast Europe and Anatolia in Prehistory: Essays in Honor of Vassil Nikolov on his 65th Anniversary. Universitätsforschungen zur prähistorischen Archäologie 293, Bonn 2016, 475-483.

vON BRAND 1702

J.-A. von Brand, Reysen durch die Marck Brandenburg, Preussen, Churland, Liefland, Pleßcovien, Groß-Naugardien, Tweerien und Moskovien. Wesel 1702.
BucK 1985

D.-W. R. Buck, Siedlungsform und Wirtschaftsstruktur bei den Stämmen der westlichen Lausitzer Kultur. In: F. HORST, B. KRÜGer (Hrsg.), Produktivkräfte und Produktionsverhältnisse in ur- und frühgeschichtlicher Zeit: I. Tagung der Fachgruppe Urund Frühgeschichte vom 14., 16.12.1981 in Berlin. Berlin 1985, 83-105.

Busch 1975

R. Busch, Die spätbronzezeitliche Siedlung an der Walkemühle in Göttingen Teil I: Archäologische Untersuchungen. Göttinger Schriften zur Vor- und Frühgeschichte 16, Neumünster 1975.

ČAPLOVIČ 1975

J. ČAPLOvič, Sídlisko lužickej kultúry v Dolnom Kubíne-Medzihradnom/Siedlung der Lausitzer Kultur in Dolný Kubín-Medzihradné, Archeologický výskum na Slovensku v roku 1974, 1975, 42-43.

ČAPLOVIČ 1978

J. ČAPLOvič, Lužické sídlisko v Dolnom Kubíne, Archeologický výskum na Slovensku v roku 1977, 1978, 70-72.

Cardona, Zammit 2015

D. Cardona, M. E. Zammit, The Bronze Age settlement at il-Qlegha tal-Bahrija, Malta: notes on the rock-cut features. In: D. TANASI, N.C. Vella (Hrsg.), The Late Prehistory of Malta: Essays on Borg in-Nadur and Other Sites. Oxford 2015, 161-171.

von Csaplovics 1829

J. von Csaplovics, Gemälde von Ungarn II. Pest 1829.

Dallmeier, Froschauer 1997

L.-M. Dallmeier, W. Froschauer, Eine urnenfelderzeitliche Siedlung und neue Gräber der Glockenbecherkultur in Burgweinting, Stadt Regensburg, Oberpfalz, Das Archäologische Jahr in Bayern 1996, 1997, 72-75.

Dalman 1933

G. Dalman, Arbeit und Sitte in Palästina III: Von der Ernte zum Mehl: Ernten, Dreschen, Worfeln, Sieben, Verwahren, Mahlen. Berlin 1933.

DeHn 1985

R. Dehn, Eine Höhensiedlung der jüngeren Urnenfelderkultur auf dem Burgberg bei Burkheim, Gemeinde Vogtsburg, Kreis Breisgau-Hochschwarzwald, Archäologische Ausgrabungen in Baden-Württemberg 1984, 1985, 53-56.

Dehn 1989

R. Dehn, Zum Fortgang der Grabung in der urnenfelderzeitlichen Höhensiedlung auf dem Burgberg bei Burkheim, Gemeinde Vogtsburg, Kreis Breisgau-Hochschwarzwald, Archäologische Ausgrabungen in Baden-Württemberg 1988, 1989, 58-62.

ECKerle, STOLl 1940

A. Eckerle, H. Stoll, Endingen (Emmendingen), Fundschau, Badische Fundberichte 16, 1940, 20

EISNER 1834

J. G. Eisner, Ueber Getreide-Silo's, Allgemeine Oesterreichische Zeitschrift für den Landwirth, Forstmann und Gärtner 6/2/46, November 1834, 1061-1065.

FüRST 2014

B. FüRST, Bronzezeitliche Speichergruben aus Walterskirchen/Passauerhof, Niederösterreich. Unveröffentlichte Masterarbeit, Universität Wien 2014

\section{GanSLMEIER 2004}

R. GANSLMEIER, Bauern zwischen Ost und West: Siedlungen der Metallzeit bei Zieko im Fläming, Archäologie in Sachsen-Anhalt 2, 2004, 202-208. 


\section{Gebers 1985}

W. Gebers, Jungbronzezeitliche und eisenzeitliche Getreidevorratshaltung in Rullstorf, Lkr. Lüneburg, ein Zeugnis urgeschichtlicher Vorratshaltung. In: K. Wilhelmi (Hrsg.), Ausgrabungen in Niedersachsen: Archäologische Denkmalpflege 1979-1984. Stuttgart 1985, 146-150.

Gebers 1997

W. Gebers, Die jungbronzezeitlichen Häuser von Ochtmissen Fundstelle 33, Stadt Lüneburg. Bautyp und funktionale Aspekte der Innengliederung der Häuser vom Typ Ochtmissen. In: J. J. Assendorp (Hrsg.), Forschungen zur bronzezeitlichen Besiedlung in Nord- und Mitteleuropa. Internationales Symposium vom 9.-11. Mai 1996 in Hitzacker. Espelkamp 1997, 60-74. GeBers 2004

W. Gebers, Rullstorf: 20 Jahre Archäologie am Rand der Elbmarsch. In: M. Fansa, F. Both, H. Hassmann (Hrsg.), Archäologie, Land, Niedersachsen: 25 Jahre Denkmalschutzgesetz: 400000 Jahre Geschichte. Archäologische Mitteilungen aus Nordwestdeutschland, Beiheft 42, Oldenburg 2004, 412-416.

GEBERs 2009

W. Gebers, Rullstorf, Abschluss der langjährigen und erfolgreichen Grabungen, Berichte zur Bodendenkmalpflege 4, 2009, 126-131. GeOrgieva 1991

Р. ГЕОрГиЕвА, Обредни ями в Тракия (края на II-I хим. пр. н. е.), Археология 33/1, 1991, 1-10.

GeORgIEva 2015

R. Georgieva, Ritual pits. In: J. Valeva, E. Nankov, D. Graninger (Hrsg.), A Companion to Ancient Thrace. Chichester 2015, 144157.

GeUPEL-SCHISCHKOFF 1987

K. Geupel-SchischкоғF, Bronzezeitliche Siedlungsreste in Walda, Kr. Großhain, Arbeits- und Forschungsberichte zur sächsischen Bodendenkmalpflege 31, 1987, 73-135.

Glaser, DöHLE 2006

H.-U. Glaser, H. J. Döhle, Eine Siedlung der späten Bronze- und frühen Eisenzeit bei Esperstedt. In: H. Meller (Hrsg.), Archäologie auf der Überholspur: Ausgrabungen an der A 38. Archäologie in Sachsenanhalt, Sonderband 5, Halle/Saale 2006, 133-147.

GÖLLER 1996

B. GÖLlER, Zwei urnenfelderzeitliche Siedlungsgruben von Hafnerbach, Flur Gänsbichl, VB St. Pölten, Niederösterreich, Fundberichte aus Österreich 34, 1996, 273-292.

Goš, Kapl, NeKVasil 1980

V. Goš, V. Kapl, J. Nekvasil, Zachraňovací akce u Palonína, Přehled Výzkumů [23]/1978, 1980, 68.

Goš, KaPl, NeKVasil 1981

V. Goš, V. KaPL, J. NeKvasil, Dokončení Zachraňovacího výzkumů v Paloníné, Přehled Výzkumů [24]/1979, 1981, 24-25.

GOVEDARICA 2000

B. Govedarica, Siedlung, Fortifikation und Wirtschaftszone: Ein Fundplatz der Göritzer Gruppe bei Rathsdorf, Landkreis Märkisch-Oderland, Archäologie in Berlin und Brandenburg 1999, 2000, 62-64.

GOVEDARICA 2006

B. Govedarica, Rathsdorf, Fpl. 5 - Eine Siedlung der frühen Göritzer Gruppe im unteren Odergebiet, Śląskie Sprawzodania Archeologiczne 48, 2006, 237-248.

VAN DE GRAAF, SARNA 2004

W.-S. VAn de GraAf, M. SARna, Vorgeschichte „Zwischen Schein und Sein“, Archäologie im Rheinland 2003, 2004, 65-66.
Griebl et al. 2017

M. Griebl, B. Biederer, T. Jachs, I. Petschro, Aktuelle Forschungen zu den Speichergruben auf der späturnenfelderzeitlichen Wallanlage von Stillfried an der March. In: F. Pieler, P. TrebsCHE (Hrsg.), Beiträge zum Tag der Niederösterreichischen Landesarchäologie 2017. Festschrift für Ernst Lauermann. Katalog des Niederösterreichischen Landesmuseums N. F. 541, Asparn/ Zaya 2017, 195-206.

Grimmer-DeHn ca. 1990

B. Grimmer-Dehn, Die urnenfelderzeitliche Siedlung auf dem Burgberg bei Burkheim. Bregenz ca. 1990.

Gringmuth-Dallmer 1996

E. Gringmuth-Dallmer, Kulturlandschaftsmuster und Siedlungssysteme: Siedlungsforschung, Archäologie-Geschichte-Geographie 14, 1996, 7-31.

Hainski, Mattheusser, Büttrer 2005

S. Hainski, E. Mattheusser, A. BütTner, Eine urnenfelder- und eisenzeitliche Großsiedlung bei Erlingen, Gemeinde Meitingen, Landkreis Augsburg, Schwaben, Das Archäologische Jahr in Bayern 2004, 2005, 56-58.

HeLleRsCHMid 2006

I. Hellerschmid, Die urnenfelder-/hallstattzeitliche Wallanlage von Stillfried an der March: Ergebnisse der Ausgrabungen 19691989 unter besonderer Berücksichtigung des Kulturwandels an der Epochengrenze Urnenfelder-/Hallstattkultur. Wien 2006.

Hellmund, Petzschmann 20 I I

M. Hellmund, U. Petzschmann, Verkohlte Getreidereste in großen Mengen. In: H. Meller (Hrsg.), Kultur in Schichten: Archäologie am Autobahndreieck Südharz (A 71), Archäologie in Sachsen-Anhalt, Sonderband 14, Halle/Saale 2011, 191-200.

HERMANN 1782

F. B. Hermann, Abriß der physikalischen Beschaffenheit der Oesterreichischen Staaten und des gegenwärtigen Zustandes der Landwirtschaft, Gewerbe, Manufakturen, Fabriken und der Handlung in denselben. Leipzig 1782.

HesKe 2003

I. Heske, Die Hünenburg bei Watenstedt, Ldkr. Helmstedt: Vorbericht über die Prospektionsgrabungen der Jahre 1998-2000, Nachrichten aus Niedersachsens Urgeschichte 72, 2003, 15-27.

Heske 2006

I. Heske, Die Hünenburg bei Watenstedt, Ldkr. Helmstedt: Eine urund frühgeschichtliche Befestigung und ihr Umfeld. Göttinger Schriften zur Vor- und Frühgeschichte 29, Neumünster 2006.

Heske 2010

I. Heske, Herrschaftssitz oder Elitenort? Zum Nachweis einer jungbronzezeitlichen Außensiedlung an der Hünenburg bei Watenstedt, Kr. Helmstedt, und ihre Bedeutung im überregionalen Vergleich. In: B. Horejs, T. L. KienLin (Hrsg.), Siedlung und Handwerk: Studien zu sozialen Kontexten in der Bronzezeit. Beiträge zu den Sitzungen der Arbeitsgemeinschaft Bronzezeit 2007 und 2008, Universitätsforschungen zur Prähistorischen Archäologie 194, Bonn 2010, 285-300.

HesKe 2016

I. Heske, Die Hünenburg-Außensiedlung bei Watenstedt, Ldkr. Helmstedt: Funde und Befunde der Ausgrabungen 2005 bis 2010. Göttinger Schriften zur Vor- und Frühgeschichte 34, Neumünster - Hamburg 2016.

Heske et al. 2010

I. Heske, S. Grefen-Peters, M. Posselt, J. Wiethold, Die jungbronzezeitliche Außensiedlung der „Hünenburg“ bei 
Watenstedt, Lkr. Helmstedt: Vorbericht über die Ausgrabungen 2005-2007, Prähistorische Zeitschrift 85/2, 2010, 159-190.

Hill, Lacey, Reynolds 1983

R. A. Hill, J. Lacey, P. J. Reynolds, Storage of barley grain in Iron Age type underground pits, Journal of Stored Products Research 19/4, 1983, 163-171.

HiRSEKORN 2003

V. Hirsekorn, Ein bronzezeitlicher Lebensbereich in der Dichtwandtrasse am Tagebau Cottbus-Nord. Ausgrabungen im Niederlausitzer Braunkohlenrevier 2001, Arbeitsberichte zur Bodendenkmalpflege in Brandenburg 11, 2003, 79-82.

HoFmann 2008

A. Hofmann, Die mittel- bis urnenfelderzeitliche Besiedlung des Fundplatzes Geiselhöring-Süd, Lkr. Straubing-Bogen, Beiträge zur Archäologie in Niederbayern 3, 2008, 123-288.

vON HOHBERg 1695

W. H. von Hohberg, Georgica Curiosa Aucta Oder: Des auf alle in Teutschland übliche Land und Haus-Wirtschafften gerichteten, hin und wieder mit vielen untermengten raren Erfindungen und Experimenten versehenen, auch einer merklichen Anzahl Kupfer weiter vermehrt und gezierten Adelichen Land- und FeldLebens. Nürnberg 1695.

Honig, SPECht, NADLER 2008

P. Honig, O. Specht, M. Nadler, Eine spätbronzezeitliche Siedlung bei Georgensgmünd, Landkreis Roth, Mittelfranken, Das Archäologische Jahr in Bayern 2007, 2008, 35-38.

Huber, Traunmüller, Haunschmid 2005

E. H. Huber, K. Traunmüller, V. Haunschmid, Wien 10, Unterlaaer Straße, Fundberichte aus Österreich 44/2005, 2006, 497-498.

Hummel, Soeters 1999

J. Hummel, G. Soeters, Speicherareal der Extraklasse: Die Ausgrabungen auf dem ETTC Gelände bei Frankfurt (Oder), Archäologie in Berlin und Brandenburg 1998, 1999, 68-71.

JÄGER, LOZEK 1978

K.-D. JÄGER, V. LOZEK, Umweltbedingungen und Landesausbau während Urnenfelderzeit in Mitteleuropa. In: W. CoBlenz, F. Honst (Hrsg.), Mitteleuropäische Bronzezeit: Beiträge zur Archäologie und Geschichte. 8. Tagung der Fachgruppe Ur- und Frühgeschichte in Dresden 1975. Berlin 1978, 211-229.

JAŠKOVÁ 1968

M. JAšKovÁ, Starolužické sídliště v Horní Moštěnici (okres Přerov), Přehled Výzkumů [12]/1967, 1968, 41.

JiRÁŇ et al. 2008

L. Jiráñ, E. Čujanová-Jílková, J. Hrala, J. Hưrková, O. ChvojKa, D. KouteckÝ, J. Michálek, V. Moucha, I. Pleinerová, Z. Smrž, V. Vokolek, Archeologie pravěkých Čech 5: Doba bronzová. Prag 2008.

KasZewski 1967

Z. KaszewsKI, Osada kultury łużyckiej z III i IV okresu epoki brązu na stanowisku 13 w Brześciu Kujawskim, pow. Włoclawek, Prace i Materiały Muzeum Archeologicznego i Etnograficznego w Lodzi 14, 1967, 159-206.

KempKen, Oehmen 2012

F. Kempken, Oenmen, Neue Hinweise zum Frühneolithikum, die linearbandkeramische Siedlung von Werl, Archäologie in Westfalen-Lippe 2011, 2012, 40-44.

KIEKEBUSCH 1923

A. Kiekebusch, Die Ausgrabung des bronzezeitlichen Dorfes Buch bei Berlin. Deutsche Urzeit 1, Berlin 1923.
KIRLEIS 2002

W. KIRLEIS, Vegetationsgeschichtliche und archäobotanische Untersuchungen zur Landwirtschaft und Umwelt im Bereich der prähistorischen Siedlungen bei Rullstorf, Landkreis Lüneburg. Dissertation, Universität Göttingen 2002.

KIRLEIS 2003

W. KirLeIs, Vegetationsgeschichtliche und archäobotanische Untersuchungen zur Landwirtschaft und Umwelt im Bereich der prähistorischen Siedlungen bei Rullstorf, Ldkr. Lüneburg, Probleme der Küstenforschung im südlichen Nordseegebiet 28, 2003, 65-132.

KIRLEIS 2004

W. KirLeis, Ein goldgelber Schatz: Der älteste Rispenhirsevorrat Niedersachsens, Archäologie in Niedersachsen 7, 2004, 42-44.

KNOLL 2012

F. KNOLL, Funktionsgruben ohne Funktion? Ein neuer Grubenofentyp aus Haldensleben Beberdüker. In: H. Meller (Hrsg.), Haldensleben, VOR seiner ZEIT: Archäologische Ausgrabungen 2008-2012. Archäologie in Sachsen-Anhalt, Sonderband 17, Halle/Saale 2012, 88-92.

KNÖRZER 1980

K.-H. KNöRzer, Subfossile Pflanzenreste aus der jüngerlatènezeitlichen Siedlung bei Laurenzberg, Gem. Eschweiler, Kr. Aachen, Bonner Jahrbücher 180, 1980, 442-457.

Kossack 1995

G. Kossack, Mitteleuropa zwischen dem 13. und 8. Jahrhundert v. Chr. Geb.: Geschichte, Stand und Probleme der Urnenfelderforschung, Beiträge zur Urnenfelderzeit nördlich und südlich der Alpen. Monographien des Römisch-Germanischen Zentralmuseums 35, Bonn 1995, 1-64.

KRÜNITZ 1788

J. G. KRÜNITZ, Oeconomische Encyclopädie, oder allgemeines System der Stats- Stadt- Haus u. Land-Wirthschaft, und der KunstGeschichte, in alphabetischer Ordnung 44, von Kopf bis KornConsumtion. Berlin 1788.

KUDRNÁČ 1958

J. KudRnÁč, Skladování obilí v jamách-obilnicích, Vznik a počátky Slovanů 2, 1958, 233-252.

KüHNHOLZ 2013

D. KüHNHOLZ, Die Anfänge der Lausitzer Kultur in Mähren und der Slowakei. Universitätsforschungen zur prähistorischen Archäologie 227, Bonn 2013.

Kuna et al. 2012

M. Kuna, N. NĚmcová, A.-L. Gentizon haller, M. Haller, V. HanykÝř, A. KloužKová, P. Kočár, L. Kovačiková, D. Malyková, Z. Mazač, M. Slabina, Z. Tempír, P. Vařeka, Z. Vlčková, P. Zemenová, Výpověd' sídlištního odpadu. Nálezy z pozdní doby bronzové $\mathrm{v}$ Roztokách a otázky depoziční analýzy archeologického kontextu/The Evidence of Settlement Discard Finds from the Final Bronze Age at Roztoky and the Depositional Analysis of Archaeological Context. Prag 2012.

Kunz 2004

L. Kunz, Obilní jámy: Konzervace obilí na dlouhý čas v historické zóně eurosibiřského a mediteránního rolnictví/Grain pits: Longtime preservation of grain in historical zone of Euro-Serbian and Mediterranean peasantry. Rolnictví na východní Moravě od baroka do II. světové války 1, Rožnov pod Radhoštěm 2004.

LeHMPUHL 2010

R. Lenmpuhl, Grab, Gruben, Grabenwerk: Ein mehrperiodiger Fundplatz bei Rathsdorf, Lkr. Märkisch-Oderland, Archäologie in Berlin und Brandenburg 2008, 2010, 40-43. 
LEHMPUHL 2012

R. Lehmpunl, Die jüngere Bronze- und frühe Eisenzeit auf dem mehrperiodigen Fundplatz Altgaul 2, Lkr. Märkisch-Oderland, Brandenburg. In: P. Łuczkiewicz, M. Meyer (Hrsg.), The Younger Generation. Akten des ersten Lublin-Berliner Doktorandenkolloquiums am 09.-10.06.2010 in Lublin. Lublin 2012, 27-54.

LINDINGER 2008

V. LiNDINGER, Urnenfelderzeitliche Siedlungen in Wien: Untersuchungen zum Siedlungswesen der älteren Urnenfelderzeit in Ostösterreich. Saarbrücken 2008.

LüNING 1991

J. LüNING, Frühe Bauern in Mitteleuropa im 6. und 5. Jahrtausend v. Chr., Jahrbuch des Römisch-Germanischen Zentralmuseums Mainz 35/1988, 1991, 27-96.

LÜNING 2000

J. LÜNING, Steinzeitliche Bauern in Deutschland: Die Landwirtschaft im Neolithikum. Universitätsforschungen zur prähistorischen Archäologie 58, Bonn 2000.

MaIse 1998

C. MaIse, Archäoklimatologie: Vom Einfluss nacheiszeitlicher Klimavariabilität in der Ur- und Frühgeschichte, Jahrbuch der Schweizerischen Gesellschaft für Ur- und Frühgeschichte 81, 1998, 197-235.

Michalski 1986

J. Michalski, Die Siedlungsgestaltung in der Lausitzer Kultur. In: D.-W. R. Buck, B. Gramsch (Hrsg.), Siedlung, Wirtschaft und Gesellschaft während der jüngeren Bronze- und Hallstattzeit in Mitteleuropa. Veröffentlichungen des Brandenburgischen Landesmuseums für Ur- und Frühgeschichte 20, Berlin 1986, 71-82. VON MÜLLER 1964

A. von Müller, Die jungbronzezeitliche Siedlung von Berlin-Lichterfelde. Berliner Beiträge zur Vor- und Frühgeschichte 9, Berlin 1964.

NestLer 1840

J. C. Nestler, Der Landwirth als Haushälter. In: J. C. LAuer (Hrsg.), Mittheilungen über die zweckmäßigste Aufbewahrung für Menschen und Hausthiere. Brno 1840, 7-271.

NikulKa 1991

F. NikulKa, Drei Hausgrundrisse vom mehrphasigen Siedlungsplatz Hitzacker-See, Ldkr. Lüchow-Dannenberg: Vorbericht zu den Grabungskampagnen 1989 und 1990, Nachrichten aus Niedersachsens Urgeschichte 60, 1991, 89-100.

Nüsse 2012

H.-J. Nüsse, Zentralort erhält Konturen: Die jungbronze- bis ältereisenzeitliche Siedlung von Rathsdorf, Lkr. Märkisch-Oderland, Archäologie in Berlin und Brandenburg 2011, 2012, 60-63.

NüSSE 2013

H.-J. NüSSE, Die befestigte Siedlung von Rathsdorf am niederen Oderbruch: Zur Charakterisierung eines zentralen Ortes der jüngeren Bronze- und frühen Eisenzeit. In: I. Heske, H.-J. NüsSE, J. SchneEweiss (Hrsg.), „Landschaft, Besiedlung und Siedlung“: Archäologische Studien im nordeuropäischen Kontext. Festschrift für Karl-Heinz Willroth zu seinem 65. Geburtstag, Göttinger Schriften zur Vor- und Frühgeschichte 33, Göttingen 2013, 127-137.

Oravecz, Mráv 2009

H. Oravecz, Z. Mráv, Jelentés az érd. Simonpuszta lelóheleyen végzett 2007. és 2008. évi leletmentésról/Report on the rescue excavations at Érd. Simonpuszta site in 2007 and 2008, Régészeti Kutatások Magyarországon 2008, 2009, 43-60.
PARMa 2004

D. Parma, Sídlištní pohřby z Ivanovic na Hané. In: O. ChvojKA (Hrsg.), Popelnicová pole a doba halštatská. Archeologické výzkumy v jižních Čechách, Supplementum 1, České Budějovice 2004, 429-450.

PARMA 2011

D. PARma, Sidelni arealy stredni a mladsi doby bronzove z trasy dalnice D1 u Vyskova/Siedlungsareale der mittleren und jüngeren Bronzezeit in der Trasse der Autobahn D1 bei Vyškov. Pravek Supplementum 22, Brno 2011.

PARMA 2015

D. PARma, Poznámky k interpretačnímu potenciálu běžných sídelních areálů doby bronzové, Studia Hercynia 19/1-2, 2015, 96-110.

PASDA 1997

C. Pasda, Von Menschen und Dünen: Ausgrabungen im Vorfeld des Tagebaus Cottbus-Nord bei Groß Lieskow, Landkreis SpreeNeiße, Archäologie in Berlin und Brandenburg 1995-1996, 1997 , $42-44$.

PASDA 2002

C. PASDA, Archäologie einer Düne im Baruther Urstromtal bei Groß Lieskow, Stadt Cottbus, Veröffentlichungen des Brandenburgischen Landesmuseums für Ur-und Frühgeschichte 33, 2002, 7-49.

PENZ 2011

M. PENz, Vorratshaltung in Erdgruben: Von einer urnenfelderzeitlichen Speichergrube in Wien-Unterlaa zu den neuzeitlichen Getreidegruben in Mitteleuropa, Fundort Wien. Berichte zur Archäologie 14, 2011, 186-201.

PERROT 1957

J. Perrot, Le Mesolithique de Palestine et les recentes decouvertes a Eynan (Ain Mallaha), Antiquity and Survival 2, 1957, 91-110.

PERrot 1960

J. Perrot, Excavations at 'Aynan ('Ein Mallaha): Preliminary report on the 1959 season, Israel Exploration Journal 10, 1960, 14-22.

PETER-RÖCHER 2011

H. Peter-Röcher, Die spätbronze-/früheisenzeitliche Siedlung in Dolgelin. Lkr. Märkisch-Oderland: Ergebnisse der Grabungen in den Jahren 2000-2004, Veröffentlichungen zur brandenburgischen Landesarchäologie 43/44, 2009/2010, 2011, 85-112.

Petrosino, Putz 2003

N. Petrosino, U. Putz, Mittel- bis spätbronzezeitliche Gefäßdepots aus Minoritenhof: Gemeinde Sinzing, Landkreis Regensburg, Oberpfalz, Das Archäologische Jahr in Bayern 2002, 2003, 38-40.

Pleinerová, Hrala 1988

I. Pleinerová, J. Hrala, Březno: Osada lidu knovízské kultury v severozápadních Čechách. Louny - Ústínad Labem 1988.

Posselt 2003

M. Posselt, Spurensuche mit dem Magnetometer an der Hünenburg. In: G. Biegel, A. Klein (Hrsg.), Die Hünenburg bei Watenstedt: Ausgrabungsergebnisse 1998-2001, Braunschweigisches Landesmuseum, Informationen und Berichte 3-4/2001, 2003, 26-29. von RauchHaupt, Schunke 2010

R. von Rauchhaupt, T. Schunke, Die jungbronze- bis früheisenzeitliche Siedlung. In: H. Meller (Hrsg.), Am Rande des Altsiedellandes: Archäologische Ausgrabungen an der Ortsumgehung Brehna. Archäologie in Sachsen-Anhalt, Sonderband 12, Halle/ Saale 2010, 57-161. 
REYNOLDS 1974

P. J. Reynolds, Experimental Iron Age storage pits: an interim report, The Prehistoric Society 1974, 40, 118-131.

REYNOLDS 1979

P. J. Reynolds, Iron-Age Farm: The Butser Experiment. London 1979.

REYNOLDS 1988

P. J. Reynolds, Pit technology in the Iron Age, British Archaeology Magazine 10, 1988, 24-26.

ROSENSTOCK 1979

D. Rosenstock, Die Siedlungsstellen in Geismar und ihre Besiedlung im oberen Leinetal seit der jüngeren vorrömischen Eisenzeit, Neue Ausgrabungen und Forschungen in Niedersachsen 13, $1979,157-311$

SAMONIG 2002

B. Samonig, Urgeschichtliche Funde aus Wien 10, Unterlaa, Fundort Wien. Berichte zur Archäologie 5, 2002, 48-74.

Schade-Lindig, Steinbring 2012

S. Schade-Lindig, B. Steinbring, Ein bandkeramischer und ein eisenzeitlicher Siedlungsplatz bei Schöffengrund-Niederwetz, Jahrbuch für Archäologie und Paläontologie in Hessen, Sonderband 1, 2012, 90-95.

SCHEIBNER 2016

A. Scheibner, Prähistorische Ernährung in Vorderasien und Europa: Eine kulturgeschichtliche Synthese auf der Basis ausgewählter Quellen. Berliner Archäologische Forschungen 16, Rahden/ Westf. 2016.

SCHINDLER 1958

R. Schindler, Die spätbronzezeitliche Siedlung in Hamburg-Boberg, Hammaburg 12, 1958, 162-187.

SChlegel, Wiegert 2006

M. Schlegel, M. Wiegert, Grube an Grube: Siedlung und Speicherareal bei Miersdorf und Zeuthen, Lkr. Dahme-Spreewald, Archäologie in Berlin und Brandenburg 2005, 2006, 56-58.

SCHLIER 1825

J. A. Schlier, Ueber unterirdische Getraid-Magazine verbunden mit Assecuranz- und Credit-Anstalten: Oder Wien kann der verderblichen Wohlfeilheit und der drückenden Theurung der verschiedenen Produkte und Lebensmittel, zugleich auch dem verderblichen Mangel an Geld und Credit für jetzt und allezeit am sichersten abgeholfen werden. Würzburg 1825.

SCHмIDT 1961

L. SснміDт, Traidgruben im nördlichen Burgenland: Aus der Arbeit am Atlas der burgenländischen Volkskunde, Burgenländische Heimatblätter 23, 1961, 142-148.

SCHMidTCHEN, GOVEDARICA, Bork 2003

G. Schmidtchen, B. Govedarica, H.-R. Bork, Besiedlung, Bodenerosion und Wasserhaushalt: Die Entwicklung einer Insel im Oderbruch bei Rathsdorf in Ostbrandenburg. In: H.-R. BORK, G. Schmidtchen, M. Dotterweich (Hrsg.), Bodenbildung, Bodenerosion und Reliefentwicklung im Mittel- und Jungholozän Deutschlands. Forschungen zur Deutschen Landeskunde 253, Flensburg 2003, 195-212.

SCHNEIDER 1974

R. U. Schneider, Jungbronzezeitliche Siedlungen in HamburgBoberg und Hamburg Lohbrügge, Hammaburg N. F. 1, 1974, $109-110$.

SCHREBER 1763

D. G. SCHREber, Sammlung verschiedener Schriften, welche die öconomischen- Policey- und cameral auch andere verwandte Wissenschaften einschlagen, Bd. 10. Halle 1763.
SCHWARZLÄNDER 2003

S. SChWARZLÄNDER, Die bronze- und kaiserzeitliche Fundstelle Pritzen 63 im Tagebau Greifenhain, Lkr. Oberspreewald-Lausitz, Veröffentlichungen zur brandenburgischen Landesarchäologie 34/2000, 2003, 61-120.

Schwellnus, Hermanns, Brown 1983

W. Schwellnus, J. Hermanns, A. Brown, Ein spätbronzezeitlicher Siedlungsplatz im Vorfeld des Tagebaus Inden, Stadt Eschweiler-Lohn, Kr. Aachen, Ausgrabungen im Rheinland 1981/82, 1983, 98-99.

SielmanN 1974

B. Sielmann, Eine spätbronzezeitliche Siedlung bei Hittfeld, Kreis Harburg, Hammaburg 1, 1974, 111-116.

Sova 1928

V. Sova, Dějiny Napajedel a blízkého okolí. Uherské Hradiště 1928. SPURNÝ 1953

V. SPunnÝ, Sídliště Věteřovského typu v Hulíně, Archeologické rozhledy 5, 1953, 452-455.

SPURNÝ 1971

V. SPuRnÝ, Lužická sídlištní keramika z Hulína (okr. Kroměříž), Přehled Výzkumů [14]/1969, 1971, 15-16.

STAHLHOFEN 1985

H. Stahlhofen, Ur- und frühgeschichtliche Siedlungsreste mit Hausgrundrissen in Wallwitz, Kr. Burg. In: D. KaufmanN (Hrsg.), Jahresschrift für mitteldeutsche Vorgeschichte 68, Berlin 1985, 235-251.

STAPELFELDT 2014

T. Stapelfeldt, Seltsamer Durchlass: Spätbronzezeitliche Siedlungsstrukturen bei Mahlow, Lkr. Teltow-Fläming, Archäologie in Berlin und Brandenburg 2012, 2014, 50-51.

STARK 2006

J. STARK, Fünfeckaxt und Doppelgefäß: Ein Siedlung der jüngeren Bronze- und vorrömischen Eisenzeit bei Waltersdorf, Lkr. Dahme-Spreewald, Archäologie in Berlin und Brandenburg 2005, 2006, 66-69.

STEINMETZ 1999

W.-D. Steinmetz, Die Hünenburg bei Watenstedt: Bronzezeitliche Siedlung und altsächsischer Adelssitz, Archäologie in Niedersachsen 2, 1999, 38-41.

SUTER 1964

K. Suter, Die Wohnhöhlen und Speicherburgen des tripolitanischtunesischen Berglandes, Zeitschrift für Ethnologie 89/2, 1964, 215-275.

Tereso et al. 2013

J. P. Tereso, P. Ramil-Rego, Y. Á. González, L. L. González, R. Almeida-DA-Silva, Massive storage in As Laias/O Castelo (Ourense, NW Spain) from the Late Bronze Age/Iron Age transition to the Roman Period: a palaeoethnobotanical approach, Journal of Archaeological Science 40, 2013, 3865-3877.

TICHÝ 1971

R. TICHÝ, Rettungsgrabung in Mohelnice als XII. Grabungssaison (Bez. Šumperk), Přehled Výzkumů [15]/1970, 1971, 8-10.

Tischler 1951

F. Tischler, Eine Siedlung der Hunsrück-Eifel-Kultur von Ochtendung, Kreis Mayen, Bonner Jahrbücher 151, 1951, 52-82.

Točí́ 1978

A. Točík, Nitriansky Hrádok, Zámeček: Bronzezeitliche befestigte Ansiedlung der Mad'arovce Kultur. Nitra 1978.

TONKOva 2010

М. Тонкова, Резултати от проучванията на Източния сектор на тракийско ямно светилище от V-началото на III в. пр. Xр. в 
м. Кузмука, с. Малко Тръново, общ. Чирпан (обект 11, JIOT

1 по ОВОС на автомагистрала „Тракия“). In: Р. Георгиева,

Т. Стоянов, А. Момчимов (Hrsg.), Югоизточна Бъмгария през II-I Химядолетие пр. Хр. Varna 2010, 198-220.

TRŇAČKOVÁ 1958

Z. TRŇAČKovÁ, Zjištovací výzkum v Hulíně, Přehled Výzkumů [3]/1958, 1958, 97.

Turková, Kuna 1987

D. TurkovÁ, M. KunA, Zur Mikrostruktur der bronzezeitlichen Siedlungen. In: E. Plest, J. Hrala (Hrsg.), Die Urnenfelderkultur Mitteleuropas. Symposium Liblice 21.-25.10.1985. Prag 1987, 217-297.

UHL 2003

U. UHL, Spare in der Zeit... Das bronzezeitliche Speicherareal von Heinersbrück 45, Landkreis Spree-Neisse, Archäologie in Berlin und Brandenburg 2002, 2003, 56-58.

UHL, BÖNISCH 2008

U. UhL, E. BöNISCH, Töpferton und Scherbenhaufen: Bronzezeitlicher Hausrat bei Klein Görigk. Ausgrabungen im Niederlausitzer Braunkohlenrevier 2007, Arbeitsberichte zur Bodendenkmalpflege in Brandenburg 20, 2008, 127-146.

UhL, BRumlich 2007

U. UHL, M. BRUMLICH, Sag mir, wo die Häuser sind: Jüngstbronzezeitliche Siedlung bei Klein Görigk, Lkr. Oberspreewald-Lausitz, Archäologie in Berlin und Brandenburg 2006, 2007, 44-46.

UsCHMANN 2000

K.-U. Uschmann, Tausendundeine Vorratsgrube, Archäologie in Deutschland 3, 2000, 38.

VARRo, De re rustica

M. T. VARRo, De re rustica / Über die Landwirtschaft, hrsg., eingel. und übers. von D. Flach. Darmstadt 2006.

VoIT 1825

J. M. VoIT, Ueber die Aufbewahrung des Getreides in Scheunen, auf Schüttböden, in hermetisch geschlossenen, mit Bleiplatten bekleideten Gewölbern und in sogenannten Silos; dann über Getreidedarren und die zweckmäßigste Construction aller hieher gehörigen Bauwerke. Augsburg - Leipzig 1825.

WAGNER 2014

T. WAGNER, Eine jungbronzezeitliche Siedlungskammer bei Haldensleben (Lkr. Börde, Sachsen-Anhalt): Fundplätze an der südlichen Peripherie des Nordischen Bronzekreises. In: B. NesseL, I. Heske, D. Brandherm (Hrsg.), Ressourcen und Rohstoffe in der Bronzezeit: Nutzung, Distribution, Kontrolle. Beiträge zur Sitzung der Arbeitsgemeinschaft Bronzezeit auf der Jahrestagung des Mittel- und Ostdeutschen Verbandes für Altertumsforschung in Brandenburg an der Havel, 16. bis 17. April 2012. Wünsdorf 2014, 147-156.

WAGNER et al. 2012

T. Wagner, M. Schrickel, A. Mehner, U. Petersen, Hektargroße jungbronzezeitliche Siedlungen. In: H. Meller (Hrsg.), Haldensleben, VOR seiner ZEIT: Archäologische Ausgrabungen 2008-2012. Archäologie in Sachsen-Anhalt, Sonderband 17, Halle/Saale 2012, 70-87.

WALTER 1962

H. G. WALTER, Traidgruben im nördlichen Burgenland, Burgenländische Heimatblätter 24, 1962, 46-47.

WANZEK 2004

B. WANZEK, Die jungbronzezeitliche Großsiedlung von Berlin-Buch: Erste Vorlage ausgewählter Funde und Befunde. II Polsko-Niemieckie Spotkania Archeologiczne Odra - przeszkoda czy pomost w ekspansji kulturowej?, Dychów 29 kwietnia-1 maja 2004 roku. Biblioteka Archeologii Środkowego Nadodrza 2, Zielona Góra 2004, 37-76.

WiLLERDING 1977

U. Willerding, Über Klima-Entwicklung und Vegetationsverhältnisse im Zeitraum Eisenzeit bis Mittelalter. In: H. JANKUHN, R. Schützeichel, F. Schwind (Hrsg.), Das Dorf der Eisenzeit und des frühen Mittelalters: Siedlungsform, wirtschaftliche Funktion, soziale Struktur. Berichte über die Kolloquien der Kommission für die Altertumskunde Mittel- und Nordeuropas in den Jahren 1973 und 1974. Abhandlungen der Akademie der Wissenschaften in Göttingen, Philologisch-Historische Klasse 3/101, Göttingen 1977, 357-405.

WILLERDING 1998

U. WILLERDING, Getreidespeicherung. In: J. Hoops (Hrsg.), Reallexikon der Germanischen Altertumskunde 1, Bd. 12, zweite Auflage. Berlin - New York 1998, 11-30.

WiLLROTH 2003

K.-H. Willroth, Die Erforschung der Hünenburg bei Watenstedt: Ein vorläufiges Resümee. In: G. BIEgeL (Hrsg.), Die Hünenburg bei Watenstedt: Ausgrabungsergebnisse 1998-2001, Braunschweigisches Landesmuseum. Informationen und Berichte $3-4 / 2001,2003,40-45$.

ZaBrana 2009

L. Zabrana, Vorratshaltung in der mykenischen Argolis als Instrument einer palatialen Zentralgewalt?, Jahreshefte des Österreichischen Archäologischen Instituts in Wien 77/2008, 2009, 375-398.

ZELENIN 1927

D. Zelenin, Russische (Ostslavische) Volkskunde. Berlin 1927.

ZeYlandowa 1963

M.Zeylandowa, Osada kulturyłużyckiejw Turbi, pow. Tarnobrzeg, Materiały Archeologiczne 4, 1963, 253-287.

Zuber 2010

J. Zuber, Die urnenfelderzeitliche Besiedlung von RegensburgBurgweinting und einschlägige Befunde aus dem ostbayerischen Donauraum, Fines Transire 19, 2010, 135-181.

ZUBER 2013

J. Zuber, Die jüngerurnenfelderzeitliche Siedlung von Burgweinting-“Kirchfeld”. Regensburger Studien 21, Regensburg 2013.

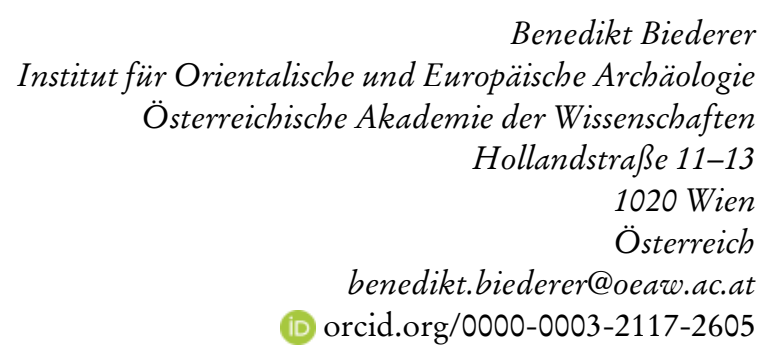


